\title{
Evaluating the effects of microphysical complexity in idealised simulations of trade wind cumulus using the Factorial Method
}

\author{
C. Dearden ${ }^{1}$, P. J. Connolly ${ }^{1}$, T. W. Choularton ${ }^{1}$, and P. R. Field ${ }^{2}$ \\ ${ }^{1}$ University of Manchester, School of Earth, Atmospheric and Environmental Sciences, UK \\ ${ }^{2}$ Met Office, Atmospheric Processes and Parametrization, Exeter, UK
}

Received: 28 September 2010 - Published in Atmos. Chem. Phys. Discuss.: 11 October 2010

Revised: 16 March 2011 - Accepted: 17 March 2011 - Published: 23 March 2011

\begin{abstract}
The effect of microphysical and environmental factors on the development of precipitation in warm idealised cloud is explored using a kinematic modelling framework. A simple one-dimensional column model is used to drive a suite of microphysics schemes including a flexible multimoment bulk scheme (including both single and dual moment cloud liquid water) and a state-of-the-art bin-resolved scheme with explicit treatments of liquid and aerosol. The Factorial Method is employed to quantify and compare the sensitivities of each scheme under a set of controlled conditions, in order to isolate the effect of additional microphysical complexity in terms of the impact on surface precipitation. At relatively low updraught speeds, the sensitivity of the bulk schemes was found to depend on the assumptions made with regards the treatment of droplet activation. It was possible to achieve a much closer agreement between the single and dual moment bulk schemes by tuning the specified droplet number concentration in the single moment scheme, suggesting that a diagnostic representation of droplet number may be an acceptable alternative to the more expensive prognostic option. However the effect of changes in $\mathrm{CCN}$ concentration were found to produce a relatively stronger effect on precipitation in the bulk schemes compared to the bin scheme; this is believed to be a consequence of differences in the treatment of drop growth by collision and coalescence. Collectively, these results demonstrate the usefulness of the Factorial Method as a model development tool for quantitatively comparing and contrasting the behaviour of microphysics schemes of differing levels of complexity within a specified parameter space.
\end{abstract}

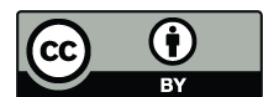

Correspondence to: C. Dearden

(christopher.dearden@postgrad.manchester.ac.uk)

\section{Introduction}

Shallow convective clouds play an important role in the global circulation and the hydrological cycle of the Earth system. Sub-tropical marine shallow cumuli, capped by the trade wind inversion, transport moisture vertically within the cloud layer, where it is subsequently detrained and transported to the tropics by the trade winds to fuel deep convection within the Inter Tropical Convergence Zone (ITCZ). The development of precipitation in trade wind cumuli is believed to be sensitive to cloud condensation nuclei $(\mathrm{CCN})$ concentrations by virtue of aerosol-cloud interactions, and such interactions could potentially have important climatological consequences (Wang and McFarquhar, 2008). Yet the overall magnitude of this sensitivity is poorly understood. Twomey (1977) showed that an increase in CCN concentration under a fixed liquid water content can lead to higher cloud droplet number concentrations but a reduction in overall droplet size. Albrecht (1989) later suggested that the reduction in size of cloud droplets as a result of the Twomey effect could potentially act to reduce the precipitation efficiency of marine boundary layer clouds. However the extent to which aerosols are able to modify cloud macroscopic properties in a buffered system such as the Earth's atmosphere is likely to be more subtle than a consideration of microphysical processes alone would suggest (Stevens and Feingold, 2009).

In principle, numerical models are useful tools to help establish and understand the complex nature of the interaction between aerosols, clouds and precipitation in the context of the trade wind regime. However, the macrostructure of shallow maritime convective cloud is poorly represented in the current generation of General Circulation Models (GCMs), and consequently such large-scale models are not a suitable basis upon which to explore such links. This has been shown most recently in a study by Medeiros and Stevens (2010), who used a conditional sampling technique to demonstrate that GCMs struggle to produce a satisfactory macrophysical

Published by Copernicus Publications on behalf of the European Geosciences Union. 
representation of the shallow cumulus cloud regime when validated against reanalysis data. The poor representation of shallow convection in GCMs stems from their reliance upon convective parameterizations, which is also believed to be responsible for the uncertainty surrounding global estimates of the climate sensitivity (Bony and Dufresne, 2005). Instead it is more appropriate to use Large Eddy Simulations (LES) at convection-permitting resolutions of $100 \mathrm{~m}$ or less to investigate the extent to which cloud microphysical processes influence the cloud macrostructure. Field campaigns such as the Rain In shallow Cumulus over the Ocean project (RICO, Rauber et al., 2007) and the INDian Ocean EXperiment (INDOEX, Heymsfield and McFarquhar, 2001) play an important role in constraining and validating LES models, (e.g., Abel and Shipway, 2007; Wang and McFarquhar, 2008). In particular, the LES intercomparison study of van Zanten et al. (2011) based on the RICO field study suggests that differences in the representation of microphysical processes is the main reason for the large variation in the timing and amount of precipitation produced between models.

LES models based on bulk microphysical parameterizations typically operate by assuming a functional form of the hydrometeor size distribution and solve prognostic equations representing the moments of the distribution, namely the mass mixing ratio for single-moment (1-m) schemes and additionally number concentration for dual-moment (2-m). Bulk schemes are cheaper to run than explicit bin schemes, but must make simplifying assumptions in order to ensure computational efficiency. As the reliance on bulk microphysics schemes is likely to continue in the future, it is becoming increasingly necessary to develop objective methods of validating their performance. This has typically been achieved via comparison against explicit bin-resolved microphysics within simple kinematic driver models. For example the study of Morrison and Grabowski (2007) used a 2-D kinematic framework to assess the performance of 2-m bulk microphysics in terms of simulating warm clouds using an explicit bin scheme as a benchmark, where both schemes assume a fixed background aerosol size distribution. They considered idealised representations of a shallow cumulus regime and a stratocumulus regime. However such regimes can themselves cover a broad range of environmental conditions, and it is important to assess the sensitivity of the microphysics to variations in the meteorological conditions as well. The observational study of Nuijens et al. (2009) assessed the sensitivity of precipitation from shallow cumulus during RICO to variations in the meteorological environment, and concluded that subtle variations in the meteorological conditions can have a strong influence on precipitation, even speculating that this may be a stronger control on precipitation than aerosol effects alone. It is fair to say that in general, the need to account for changes in meteorology when using LES models to evaluate microphysical sensitivities has been somewhat overlooked. Recent exceptions include the work of Wang and McFarquhar (2008) and
Teller and Levin (2008). In the case of the latter, the Factorial Method (FM) was used to quantify the sensitivity of precipitation in simulations of mixed-phase convective cloud when both meteorological and microphysical factors occur synergistically. The technique of isolating the effects of individual factors in the context of atmospheric modelling was pioneered by Stein and Alpert (1993). Dearden (2009) proposed to expand the use of the FM across a hierarchical suite of microphysics schemes within a one dimensional kinematic framework, consisting of a bulk scheme with the choice of both 1-m and 2-m liquid water, and an explicit bin scheme with prognostic treatment of aerosol, capable of accounting for the effects of aerosol composition. Such a method allows the macroscopic forcing conditions to be easily constrained, and is adopted here in relation to quantifying the impact of microphysical complexity on precipitation development in the context of idealised shallow cumulus cloud. The sensitivity of the bulk schemes can be quantified and compared to that of the bin scheme such that it may be possible to isolate those meteorological regimes where the additional microphysical complexity is warranted. It is important to note that the nature of the 1-D kinematic framework is such that it does not permit feedbacks between microphysics and dynamics and thus does not provide a complete representation of cloud dynamics. Whilst the importance of feedback effects are recognised, they also make it difficult to isolate differences that arise purely from the treatment of microphysics and potentially other factors (such as the numerical treatment of advection), and so an idealised study in the absence of feedbacks is beneficial in terms of identifying and understanding the potential limitations of simpler bulk parameterizations. The simplicity of the driver model also allows for a greater number of sensitivity tests to be performed compared to 3-D simulations due to the reduced computational burden. Finally simple 1-D frameworks have very recently been used to develop our understanding of rain formation in shallow cumulus clouds (Seifert and Stevens, 2010), and also to develop improved parameterizations of rain evaporation for use in dual-moment bulk schemes (Seifert, 2008), which demonstrates their usefulness as a tool for advancing our understanding in this area.

This paper is organised as follows. A description of the microphysics and the idealised driver model are presented in Sect. 2. Section 3 considers the details of the experimental design based on the FM. The results from each microphysics scheme are analysed and compared in Sect. 4, and the potential implications of these findings are addressed in Sect. 5, including a discussion of how feedbacks between microphysics and dynamics may potentially modify the sensitivities shown. 


\section{Model configuration}

The suite of microphysical schemes considered for testing are embedded within a 1-D column framework, within which the initial temperature and humidity profiles are prescribed, along with the vertical velocity field responsible for producing the supersaturation necessary for cloud formation. The hierarchy of microphysical complexity ranges from a fully explicit treatment of liquid water and aerosol to a bulk parameterization of warm rain processes with the option of both 2-m and 1-m cloud liquid water. A detailed description of each of the schemes considered is now given, starting with the bin microphysics.

\subsection{Bin microphysics}

The bin scheme used in this study is the Aerosol-CloudPrecipitation-Interaction-Model (ACPIM), developed at the University of Manchester. ACPIM is a state-of-the-art process model that has been created primarily to study the effects of aerosol on mixed-phase cloud as part of the core modelling suite for the Aerosol Properties Processes And InfluenceS on the Earth's climate (APPRAISE) project. For the purpose of this study its use is restricted to liquid-only processes. The ACPIM model supports a prognostic treatment of aerosol, allowing the effects of the aerosol size distribution and also composition to be explored; this feature was used in the simulations performed for this study. Activation of droplets in ACPIM is based on Köhler theory. 147 mass bins are used to resolve the liquid drop size distribution, and 154 are used for aerosol. The ambient supersaturation is resolved using a variable sub-step to ensure it is captured to a sufficient level of accuracy, regardless of the choice of the main model timestep. Each aerosol bin solves prognostic equations for the mass and number of aerosols. Condensation occurs continuously via the droplet growth equation (Pruppacher and Klett, 1997), where the equilibrium vapour pressure is supplied by Köhler theory using data from a thermodynamic model (ADDEM, Topping et al., 2005). The growth equation is solved explicitly using the Variablecoefficient Ordinary Differential Equation solver (VODE) available from the netlib repository (www.netlib.org). Initial growth of the cloud droplets is dominated by the diffusional growth equation, and subsequent growth to rain drop size through the collision-coalescence process is handled by explicitly solving the 2-D stochastic collection equation (Bott, 2000), with the collision efficiency based on the look up table by Hall (1980). In the version of ACPIM used for this study, the efficiency of coalescence is taken to be unity, such that the overall collection efficiency is equal to the Hall collision efficiency. In terms of gas kinetic effects, the condensation coefficient in all cases is taken to be unity, based on Laaksonen et al. (2005).

For this study, a single log-normal aerosol size distribution is used with a geometric standard deviation of 1.28 , and a geometric mean diameter of 0.06 microns. These values are based on the bimodal distribution defined in the RICO model intercomparison study (van Zanten et al., 2011); the giant mode was found to have minimal impact on precipitation for the range of $\mathrm{CCN}$ concentrations considered. In terms of the aerosol composition, pure sea-salt was assumed in all cases. Tests with ammonium sulphate were also performed, although the effect on precipitation was found to be small, with only a slight increase in rain at lower updraught speeds.

\subsection{Bulk microphysics}

The bulk scheme is based on a liquid-only version of the scheme described in Morrison et al. (2005), such that the two classes of hydrometeor considered are cloud liquid water and rain. The scheme is a flexible multi-moment scheme, allowing the choice of either a $1-\mathrm{m}$ or $2-\mathrm{m}$ treatment for liquid droplets. The scheme also contains different options for the treatment of droplet activation in the 2-m liquid case.

Saturation adjustment is used in the bulk schemes, such that any water vapour present above $100 \%$ relative humidity is assumed to instantaneously condense onto existing cloud droplets. Such an assumption is appropriate because the mass of water vapour above saturation is typically much smaller than the mass of cloud water. The autoconversion and accretion schemes used in all cases are those of Khairoutdinov and Kogan (2000), henceforth referred to as the KK scheme. A radius of 25 microns is used to separate the cloud liquid water and rain categories. The microphysical process rates in the KK scheme are formulated via multiple nonlinear regression of simulated spectra from LES studies of marine boundary layer clouds, and so are considered to be an appropriate choice for this study. Self-collection of rain drops is also accounted for, and is based on the parameterization specified in Seifert and Beheng (2001). Self-collection of rain drops is potentially an important process; indeed the LES study of shallow convection by Stevens and Seifert (2008) suggests that bulk schemes which do not include a parameterization of self-collection are more likely to exhibit higher evaporation rates due to having rain drop spectra that contain higher concentrations of smaller rain drops.

In all cases, a 2-m scheme is used for rain. Dearden (2009) had originally proposed to include a $1-\mathrm{m}$ treatment for rain as well, but this was not included in the final experimental design because it was not possible to identify a single value of the rain intercept parameter that was appropriate for different values of droplet number concentration. The benefits of $2-\mathrm{m}$ rain over 1-m rain have been well documented recently, e.g. in the studies by Morrison et al. (2009), although Shipway and Hill (2011) and references therein suggest that 2-m rain schemes with an invariant shape parameter can suffer from the problem of excessive size-sorting.

The particle size distribution for both rain and cloud liquid water is defined by a gamma distribution (Straka, 2009) of the form 
$n(D)=N_{0} D^{\mu} e^{-\lambda D}$

where $n(D)$ is the number concentration for a given particle diameter size $D$; the integral of Eq. (1) with respect to $D$ gives the total number concentration, $N_{T}$. $N_{0}$ is the intercept parameter, $\lambda$ is the slope parameter and $\mu$ is the shape parameter. $N_{0}$ is determined as a function of the total number concentration

$N_{0}=\frac{N_{T} \lambda^{\mu+1}}{\Gamma(\mu+1)}$

For rain, $\mu$ is set to zero, which reduces Eq. (2) to an exponential distribution (Marshall and Palmer, 1948), such that $N_{0}=N_{T} \lambda$.

Terminal fall speeds for rain are given by the following

$V_{r}(D)=\left(\rho_{0} / \rho\right)^{g_{r}} a_{r} D^{b_{r}} e^{f_{r} D}$,

where $\rho_{0}$ is the density of air at sea level, and the constants $a_{r}, b_{r}, f_{r}$ and $g_{r}$ are set to $841,0.8,0.0$ and 0.54 respectively, following Liu and Orville (1969).

The different combinations of the bulk scheme are now presented, starting with the simplest level of complexity.

\subsubsection{1-m liquid, 2-m rain}

In the simplest treatment considered here, only one prognostic variable is used to represent cloud liquid water (the mass mixing ratio), and the droplet number concentration is taken as a constant in the calculation of the intercept parameter in Eq. (2). The experimental set up of the 1-m scheme is such that the assumed droplet number concentration is taken to be equal to the $\mathrm{CCN}$ concentration, with the implicit assumption that all available $\mathrm{CCN}$ activate to form cloud droplets.

\subsubsection{2-m liquid (Twomey activation), 2-m rain}

Moving from 1-m to 2-m liquid grants the ability to predict droplet number, thus requiring an explicit term representing activation of cloud droplets. The consequence of this is that in the 2-m scheme, not all available $\mathrm{CCN}$ are necessarily activated for a given updraught speed, which may lead to lower droplet number concentrations when compared to the 1-m scheme. The first treatment of droplet activation considered is based on the parameterization of Twomey (1959), which in Rogers and Yau (1989) is approximated as:

$N_{\mathrm{CCN}} \approx 0.88 c^{2 /(k+2)}\left[7.10^{-2} w^{3 / 2}\right]^{k /(k+2)}$

where $w$ is the grid-scale vertical velocity in $\mathrm{cms}^{-1}$ and the number concentration of active $\mathrm{CCN}$ is $N_{\mathrm{CCN}}$, in $\mathrm{cm}^{-3}$. The variables $c$ and $k$ are activation parameters where $c$ represents the number concentration of $\mathrm{CCN}$ active at $1 \%$ supersaturation and $k$ represents the ease with which droplets form. In this study, a value of 0.4 is used for $k$ based on measurements of tropical maritime airmasses (Pruppacher and Klett, 1997).

\subsubsection{2-m liquid (Abdul-Razzak activation), 2-m rain}

The second option for droplet activation is based on the parameterization of Abdul-Razzak et al. (1998), henceforth identified as A-R, which assumes a single log-normal aerosol size distribution for a given chemical composition, requiring knowledge of the geometric mean radius of aerosol particles and the standard deviation. This information is then used to parameterise the maximum supersaturation in the rising air parcel given the vertical velocity, which in turn determines the fraction of aerosols activated to form cloud droplets. The aerosol log-normal parameters used are the same as those employed to initialise the bin model, as is the assumed chemical composition. By repeating the 2-m liquid simulations using the A-R scheme for droplet activation, it will be possible to quantify the benefits of explicitly specifying the aerosol log-normal parameters, albeit assuming a fixed form. Dearden (2009) had originally proposed the option of a prognostic treatment of aerosol for the bulk scheme; however this was not considered due to time constraints. The possibility of a 2-m aerosol scheme coupled to the 2-m bulk microphysics will be revisited in future work on the subject.

The only difference between the 2-m schemes is in terms of the droplet activation scheme used. For cloud base activation, droplet number in the A-R scheme is determined as a function of both the updraught speed and the aerosol properties. This is different from the Twomey approach, which determines cloud base droplet number based on the updraught speed and the value of the chosen $c$ and $k$ parameters. In both the Twomey and A-R cases, in-cloud activation is also permitted, and is based on a diagnostic calculation of the in-cloud equilibrium supersaturation within the current timestep. This diagnostic relation is a feature of the Morrison scheme, and should a supersaturation be diagnosed, incloud activation is allowed to occur via the specified activation scheme.

\subsection{Driver model configuration}

The bulk microphysics are driven using the 1-D Kinematic Driver Model, KiD (Shipway and Hill, 2011) whilst the ACPIM microphysics is currently embedded within its own 1-D column model. To obtain consistency with ACPIM, some changes have been made to the standard $\mathrm{KiD}$ model to ensure consistency between driver models, thus ensuring that both bin and bulk microphysics schemes can be compared rigorously. The details of the necessary changes in the KiD model are now presented.

\subsubsection{Advection}

The advection scheme common to both driver models is a 4th order, positive definite, monotonic scheme (Bott, 1989, 1992). The Bott scheme is used to advect vapour and liquid water. The default advection scheme in the KiD model is the 
Total Variance Diminishing (TVD) scheme of Leonard et al. (1993) known as ULTIMATE, but for the purpose of this study the Bott scheme is used for consistency with ACPIM. There is no advection of potential temperature in the column; indeed the potential temperature and pressure fields are held fixed such that the microphysics is not permitted to influence the evolution of the dynamics. This was deemed necessary such that the pure microphysical behaviour of each scheme could be compared fairly, in the absence of thermodynamic feedbacks. A slight caveat is in the handling of sedimentation. The ACPIM driver model is configured to combine sedimentation with vertical advection due to air motion in a single calculation, which is handled using the 4 th order Bott scheme. In KiD, sedimentation of cloud liquid water and rain is handled within the Morrison microphysics scheme itself using a timesplit 1st order upwind method, where a size threshold of 50 microns diameter is used to separate cloud liquid water from rain. The potential implications of these differences are addressed in Sect. 4.3.

\subsubsection{Initialisation of thermodynamics}

Both models accept inputs for potential temperature and vapour mixing ratio at specified height levels; this defines the initial thermodynamic profiles. These points are then linearly interpolated onto the model vertical grid at every level. The model then converts from potential temperature to absolute temperature to pass to the microphysics, for which it needs the pressure field. Pressure is obtained by solving the following first-order differential based on the hydrostatic equation and the ideal gas law:

$$
\frac{d p}{d z}=\frac{-p g}{R T}
$$

Equation (5) is solved based on Press et al. (2007) in both KiD and ACPIM.

\section{Experimental design}

\subsection{Initial conditions and idealised forcing}

The forcing for the idealised warm shallow cumulus case is based on the "warm1" configuration as defined in the KiD documentation which can be downloaded from http: //appconv.metoffice.com/microphysics/doc.html. It consists of a single updraught, constant in height and sinusoidal in time:

$w(z, t)= \begin{cases}w_{1} \sin \left(\pi t / t_{2}\right) & \text { if } t<t_{2} \\ 0.0 & \text { if } t>t_{2}\end{cases}$

The timescale $t_{2}$ is dependent upon the peak updraught speed, $w_{1}$, such that $t_{2}=1200 / w_{1}$. For a peak updraught speed of $0.5 \mathrm{~ms}^{-1}$, this would result in the vertical velocity field reducing to zero after $2400 \mathrm{~s}$. Thus values of $w_{1}$ greater

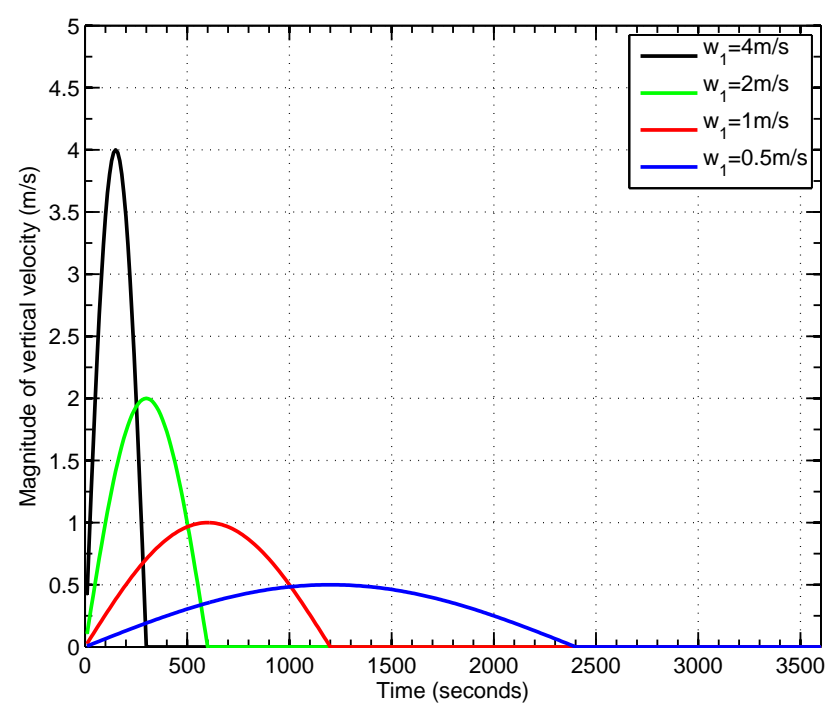

Fig. 1. Vertical velocity fields as a function of time, as applied to the 1-D column equally at every vertical level.

than $0.5 \mathrm{~ms}^{-1}$ would reduce the timescale over which the updraught is applied. The evolution of the updraught velocity with time for different values of $w_{1}$ is plotted in Fig. 1, as applied equally at every vertical level.

The warm 1 case is based on the composite profile used to initialise models for the GCSS RICO intercomparison. However, as noted in Shipway and Hill (2011), there is a slight issue with simulations based on the warm 1 profile in that the resulting profile of liquid water content decreases with height after reaching a maximum above cloud base, which is not necessarily realistic for a warm shallow convective cloud. This is a consequence of the fact that the whole column is lifted in response to the vertical velocity field, where at a given timestep the applied vertical velocity is the same at every gridpoint. The relative humidity reaches a peak at around $750 \mathrm{~m}$; at grid points above this height, the relative humidity begins to decrease such that the amount of water vapour available for condensation is reduced, leading to a slight reduction in liquid water content with height. Despite this, and given the highly idealised nature of the 1-D framework to begin with, the warm 1 profile still acts as a suitable basis upon which to conduct a comparison of different microphysics schemes. The reader is made aware that in the 1-D intercomparison of Shipway and Hill (2011), the lowest levels of the warm 1 profile were made slightly drier, to produce a liquid water content profile that increased with height and an overall reduction in liquid water path. This produced a reduction in surface precipiation totals relative to the original warm1 profile, given the same peak updraught velocity.

Changes in temperature are considered such that the warm1 profile is shifted to cooler temperatures resulting in a constant cooling with height whilst keeping the relative humidity fixed. The result is such that changes in 


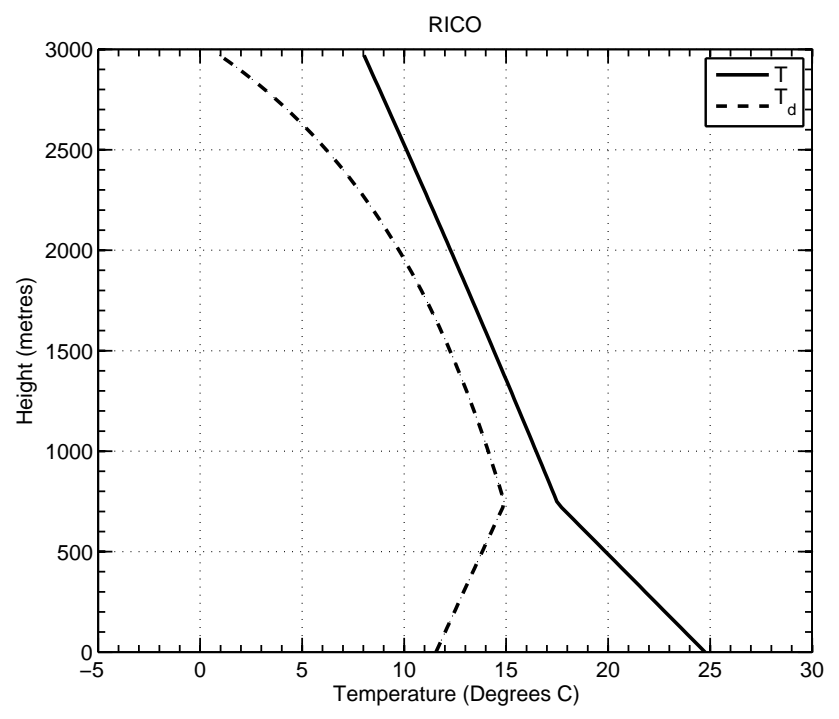

Fig. 2. Temperature (solid) and dew-point temperature (dashed) profiles in ${ }^{\circ} \mathrm{C}$ taken from the RICO model intercomparison, and used to initialise the models. The additional profiles, "RICO-2" and "RICO-5", are obtained by cooling the RICO profile uniformly in height by $2{ }^{\circ} \mathrm{C}$ and $5^{\circ} \mathrm{C}$ respectively under a fixed relative humidity.

thermodynamics do not affect the cloud height or depth. The temperature profile used in this study is plotted in Fig. 2. In all cases, the simulations are left to run for long enough until they have finished precipitating (typically two hours) and diagnostic output is available at the end of each timestep (every $5 \mathrm{~s}$ ). The vertical grid spacing in both models is set to $30 \mathrm{~m}$, with 100 levels giving a domain height of $3 \mathrm{~km}$.

\subsection{Experimental design for the Factorial Method}

The experimental design based around the FM is now presented. It should be noted that changes in meteorological factors, namely the temperature profile and updraught velocity, are treated consistently in each scheme; however the choice of microphysical factors to explore depends on the level of complexity of the microphysics scheme in question. The factorial design is based around the $2^{n}$ design, meaning two values, arbitrarilly labelled "low" and "high", are assigned to $n$ number of factors, and the effect of changing from the "low" to the "high" value is calculated for each factor. Values for each factor are chosen such that the effect of moving from the "low" value to the "high" value acts to reduce the amount of precipitation reaching the surface. Thus each factor can be evaluated in terms of its percentage contribution to precipitation suppression. In some cases, repetitions of the $2^{n}$ design are considered to allow the effect of more than one "high" value to be explored.
Table 1. Design matrix for the general $2^{3}$ factorial design.

\begin{tabular}{lcccc}
\hline Run & A & B & C & Labels \\
\hline 1 & - & - & - & (one) \\
2 & + & - & - & $a$ \\
3 & - & + & - & $b$ \\
4 & + & + & - & $a b$ \\
5 & - & - & + & $c$ \\
6 & + & - & + & $a c$ \\
7 & - & + & + & $b c$ \\
8 & + & + & + & $a b c$ \\
\hline
\end{tabular}

\subsubsection{General example: $2^{3}$ design}

Consider the following general example based on 3 factors, labelled A, B and C respectively, each at two levels, yielding a $2^{3}$ design. Thus eight treatment combinations (experiments) would be necessary to fulfill the requirements of the study. To denote low and high values, the geometric notation system is used such that " -" indicates low and "+" indicates high, and the eight runs required in the $2^{3}$ design are given in Table 1. Table 1 also writes the treatment combinations based on the labelling system of lowercase letters, which in standard order is written as (one), $a, b, a b, c, a c, b c$ and $a b c$. In this system, the presence of a lowercase letter represents the high value of that factor, and the absence of a letter denotes the low value. The label (one) is reserved for the case when all factors are at their low value. Using the lowercase letter labels, it is possible to write down expressions for the main effects; that is, the average effect of each factor due to the change in value from low to high. Similar expressions for the interactions between main effects can also be derived. For full details on the calculation of the main effects and interaction terms based on a general $2^{3}$ design, the reader is referred to Dearden (2009) and references therein. Once the main effects and interaction terms have been calculated, the relative contribution of each effect or interaction to the total variance can also be quantified in terms of a percentage of the total sum of squares. The calculation of the sum of squares for a given effect or interaction term is also specified in Dearden (2009).

\subsubsection{Factorial design for bin microphysics}

Table 2 summarises the factorial design for the ACPIM model. A $2^{3}$ design is used, giving three factors in total, two of which, namely $w_{1}$ and $T$, are meteorological in nature and represent vertical velocity and the ambient temperature respectively. The remaining factor, $\mathrm{CCN}$, is a microphysical factor which represents the number concentration of the aerosol present within the column at each vertical level. 36 numerical simulations are required to fulfill the design presented in Table 2. The CCN factor is designed to explore the 
Table 2. Summary of the factorial design for the bin microphysics.

\begin{tabular}{lll}
\hline Factor & Description & Values \\
\hline$w_{1}$ & Peak vertical velocity $\left(\mathrm{ms}^{-1}\right)$ & $0.5,1,2,4$ \\
$T$ & Temperature Profile & RICO, RICO-2, RICO-5 \\
$\mathrm{CCN}$ & Aerosol no. concentration $(/ \mathrm{cc})$ & $50,100,200$ \\
\hline
\end{tabular}

effect of increasing the aerosol number concentration from a starting value of 50/cc, whilst the geometric mean radius and standard deviation as defined in Sect. 2.1 are held constant.

\subsubsection{Factorial design for bulk microphysics}

Table 3 summarises the factorial design for the bulk microphysics, also based around a $2^{3}$ design and requiring 135 simulations in each case. The reduced computational burden of the bulk parameterizations compared to the bin scheme is exploited to perform a more thorough exploration of the parameter space. The meteorological factors $w_{1}$ and $T$ are defined to be the same as in the bin scheme, although the $w_{1}$ factor covers a greater range of values. In the 2-m bulk scheme, the $\mathrm{CCN}$ factor relates to the maximum droplet number concentration permitted. For 2-m Twomey, this is equal to the value of $c$ in Eq. (4). For 2-m A-R, the CCN factor relates to the aerosol number concentration based on the unimodal log-normal distribution, as in the bin scheme. In the $1-\mathrm{m}$ scheme, the $\mathrm{CCN}$ factor is simply the prescribed value of droplet number, which implicitly assumes that all available aerosol have activated to form cloud droplets. It should be noted that no attempt was made to tune the bulk schemes to the bin scheme prior to running the experiments. It should also be recognised that the choice of $c$ and $k$ parameters in the Twomey case implies a different aerosol spectrum compared to that used in the other schemes, which could contribute to differences in droplet number concentration, most notably at low updraught speeds.

\section{Results}

\subsection{Initial analysis of cloud fields}

To illustrate the equality of the driver models, tests were performed based on both the bulk and bin microphysics with precipitation and sedimentation processes switched off, such that the only microphysical processes permitted are condensation and evaporation. The resulting liquid water paths from each scheme are plotted in Fig. 3. It can be seen that the curves agree so closely that they appear to be coincident, which confirms the consistency of the forcing conditions between driver models (and also confirms the validity of the saturation adjustment approach used in the bulk schemes). It can also be concluded from this result that, once precipitation

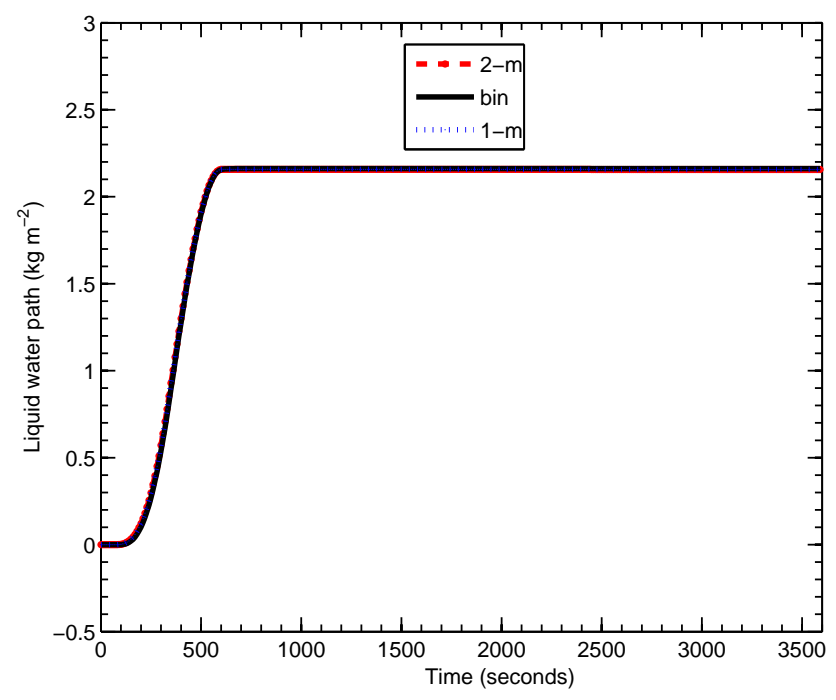

Fig. 3. Timeseries of liquid water path from the 1-m, 2-m A-R and bin schemes in the absence of precipitation and sedimentation, such that all condensed water stays in the cloud. The results shown were obtained with the following settings: $w_{1}=2 \mathrm{~ms}^{-1}, T=$ RICO and $\mathrm{CCN}=100 / \mathrm{cc}$.

and sedimentation are permitted to occur, any subsequent differences in cloud liquid water path can be attributable to the treatment of these processes.

Figure 4 shows time-height plots from the bin and 2-m A$\mathrm{R}$ schemes with precipitation and sedimentation enabled, for $w_{1}=2 \mathrm{~ms}^{-1}, T=\mathrm{RICO}$ and $\mathrm{CCN}=100 / \mathrm{cc}$. In both cases, the dynamical forcing conditions produce a cloud whose base is around $500 \mathrm{~m}$ and a top at $2 \mathrm{~km}$. As the prescribed updraught reduces to zero, and in the absence of any parameterised entrainment effects or negative vertical velocities, a thin residual layer of cloud is allowed to persist in a steady state. Admittedly this is not realistic; indeed Seifert and Stevens (2010) showed that the finite lifetime of shallow cumulus cloud is an important timescale in determining precipitation efficiency. However this shortcoming does not impinge upon the ability of the model to reveal interesting differences in the behaviour of the chosen microphysics schemes. Furthermore, the influence of the residual cloud layer on the precipitation rate is minimal because the droplets that remain are too small for effective collision and coalescence to occur, and so there is no real concern of any possible contamination issues arising from this deficiency.

To allow comparison of rain mixing ratios, the bin scheme diagnoses rain based on those liquid drops greater than 50 microns in diameter, in accordance with the KK scheme. The results share some similarities with those of Seifert and Stevens (2010), who used a similar 1-D model to compare an alternate pair of bin and 2-m bulk microphysics schemes with each other, but some differences as well. For instance, both studies show that the bulk scheme is able to capture the height and time of rain formation reasonably well. However 
Table 3. Summary of the factorial design for the bulk microphysics.

\begin{tabular}{lll}
\hline Factor & Description & Values \\
\hline$w_{1}$ & Peak vertical velocity $\left(\mathrm{ms}^{-1}\right)$ & 0.5 to 4 in intervals of 0.25 \\
$T$ & Temperature Profile & RICO, RICO-2, RICO-5 \\
$\mathrm{CCN}$ & Aerosol number concentration /cc (2-m A-R) & $50,100,200$ \\
& No. of droplets active at $1 \%$ supersaturation /cc (2-m Twomey) & \\
& Droplet number concentration /cc (1-m) & \\
\hline
\end{tabular}
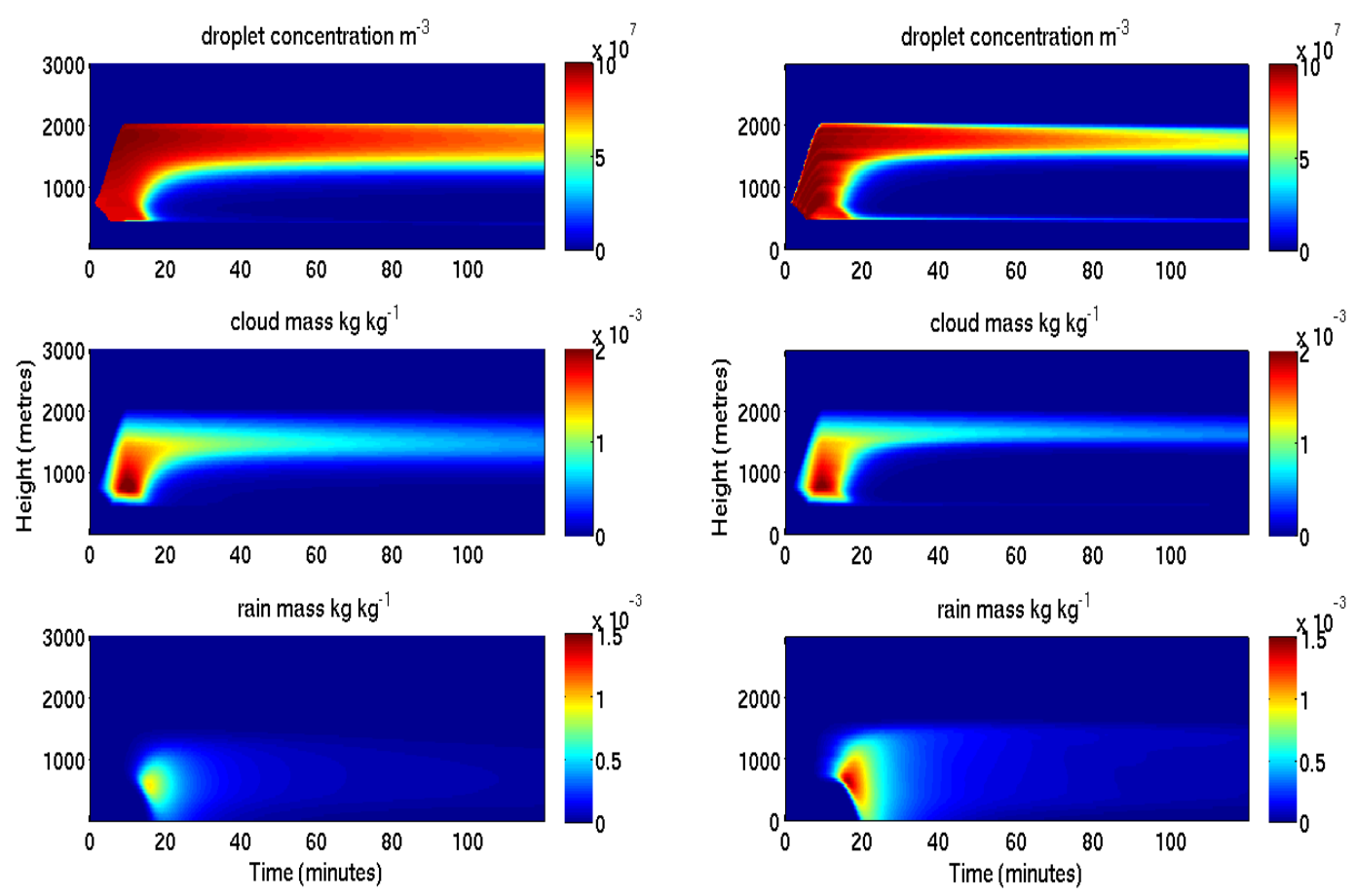

Fig. 4. Comparison of cloud droplet number concentration $\left(\mathrm{m}^{-3}\right)$, cloud mass mixing ratio $\left(\mathrm{kg} \mathrm{kg}^{-1}\right)$ and rain mixing ratio $\left(\mathrm{kg} \mathrm{kg}^{-1}\right)$ from the 2-m A-R scheme (left) and the bin scheme (right). The results shown are taken from simulations with $w_{1}=2 \mathrm{~ms}-1, T=\mathrm{RICO}$ and $\mathrm{CCN}=100 / \mathrm{cc}$.

in this particular study, Figs. 4 and 5 show that the bin simulation converts more of the cloud to rain than the bulk scheme. Given that the liquid water paths are essentially the same in the absence of precipitation processes as shown in Fig. 3, this suggests that the collision-coalescence process in the ACPIM bin scheme is more efficient at producing rain compared to the $\mathrm{KK}$ autoconversion and accretion schemes. The implications of the larger rain water path in the bin scheme are addressed later in Sect. 4.3.

It should also be remembered that the bulk scheme uses an exponential size distribution for rain, which implicitly assumes a shape parameter of zero. It is possible to test the validity of this assumption using the bin scheme; this is accomplished by fitting a gamma function to the resolved size distribution and diagnosing $\mu$ for rain through consideration of those drops greater than or equal to 50 microns in diameter.
This is achieved through the method of moment-conserving fits, the mathematics of which are derived in Appendix A. Figure 6 plots the evolution of the diagnosed shape parameter with height and time from the bin scheme. The magnitude of $\mu$ varies considerably through the evolution of the cloud; around the onset of in-cloud rain formation, $\mu$ is close to zero, but values of $\mu$ are consistently higher below cloud base. This result is important since a varying shape parameter has implications for rates of sedimentation (Milbrandt and McTaggart-Cowan, 2010) and evaporation, which could be significant in full 3-D simulations when feedbacks between microphysics and dynamics can influence the temperature of the sub-cloud layer. The deficiencies of assuming a fixed $\mu$ value of zero are also discussed in Stevens and Seifert (2008). 

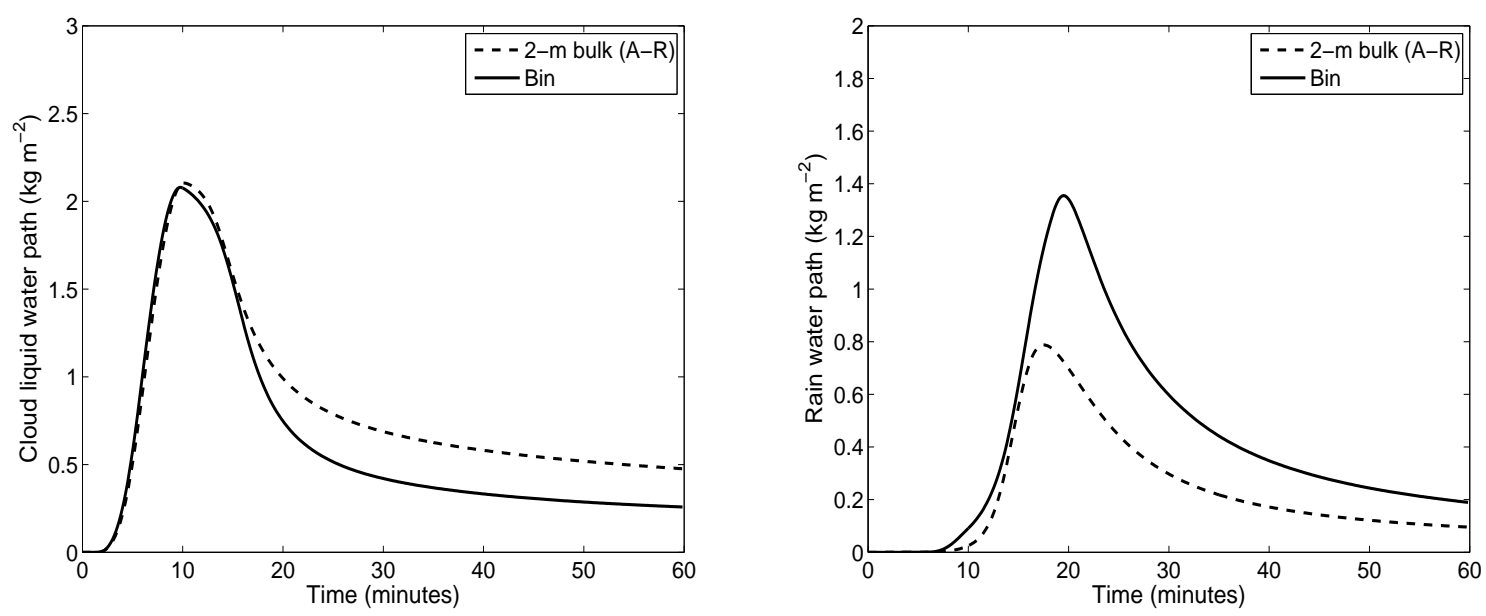

Fig. 5. Comparison of cloud liquid water path (left) and rain water path (right) in $\mathrm{kgm}^{-2}$ from the $2-\mathrm{m}$ A-R scheme (dashed) and bin scheme (solid), for those simulations shown in Fig. 4.

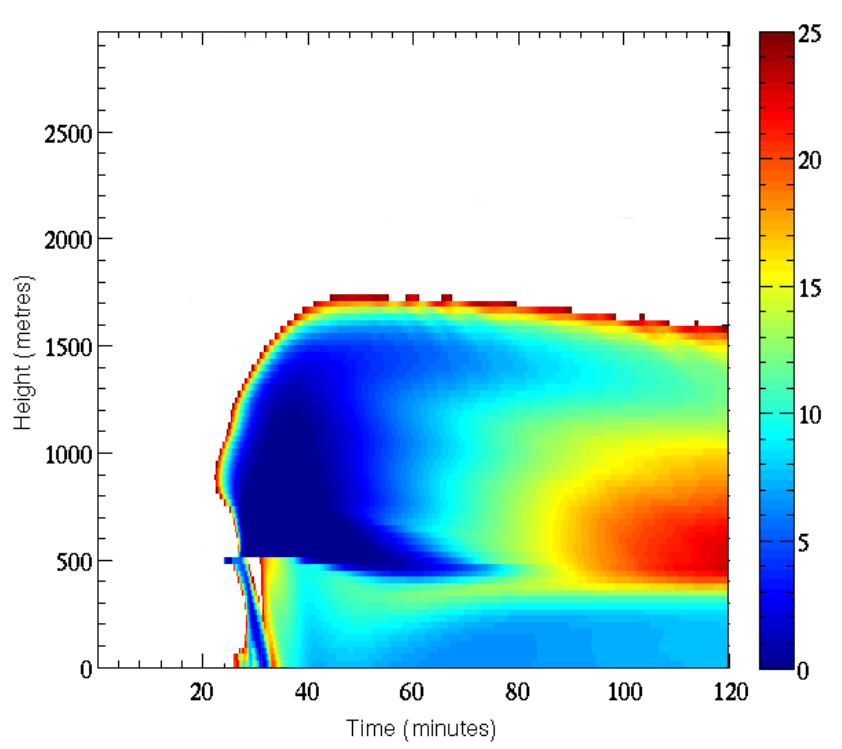

Fig. 6. Time-height plot of the diagnosed shape parameter for rain from the bin scheme, obtained through the method of momentconserving fits (see Appendix A). The plot shown is from the $\mathrm{CCN}=50 / \mathrm{cc}$ case, with $w_{1}=0.5 \mathrm{~ms}^{-1}$ and $T=$ RICO profile.

\subsection{Comparison of total precipitation}

Table 4 shows the total precipitation amounts (in $\mathrm{mm}$ ) for a subset of the total number of experiments from all four schemes. The nature of the table allows for comparison of each scheme as a function of changing $\mathrm{CCN}$ concentrations, cloud base updraught speeds and temperature profiles. Before a more rigorous analysis of this data is performed using the FM, some broad observations can first be made. With regard the 1-m scheme, the assumption of a fixed droplet number means that the total precipitation is essentially in- sensitive to vertical velocity; however in the other schemes, an increase in the magnitude of vertical velocity generally produces a reduction in the total amount of precipitation produced, with some minor exceptions to this pattern at low updraught speeds. This is a consequence of the ability of the other three schemes to predict droplet number; not all CCN are necessarily activated as cloud droplets for a given updraught. The reduction of precipitation towards larger updraughts can be attributed to aerosol indirect effects, since stronger vertical velocities activate more $\mathrm{CCN}$ which in turn reduces the precipitation efficiency (the reader is reminded that by design, the maximum extent the column is lifted is the same regardless of the updraught speed; this explains why precipitation amounts do not increase with higher vertical velocities). It can also be seen that as vertical velocity is increased in the 2-m schemes, the total precipitation amounts begin to converge on those from the $1-\mathrm{m}$ scheme. It is worthy of note that in some instances, an increase in $w_{1}$ from $0.5 \mathrm{~ms}^{-1}$ to $1 \mathrm{~ms}^{-1}$ actually results in a slight increase in precipitation. This is because some of the $0.5 \mathrm{~ms}^{-1}$ simulations are still producing small amounts of drizzle at the end of the integrations, and so have not quite finished precipitating by the time the simulations are stopped. Thus precipitation totals appear slightly underestimated in these cases. All four schemes agree, at least in a qualitative sense, on a reduction in precipitation amount as a function of cooling temperature. This is because under a fixed relative humidity, the available source of water vapour that is converted to liquid water during condensation is reduced as the temperature profile cools.

Figures 7 and 8 plot the precipitation rate and accumulated precipitation totals respectively as a function of time, for those experiments highlighted in bold in Table 4. Figure 7 reveals that all four schemes show a delay in the onset of precipitation as a function of reducing vertical velocity. The timing of surface precipitation is quite similar between 

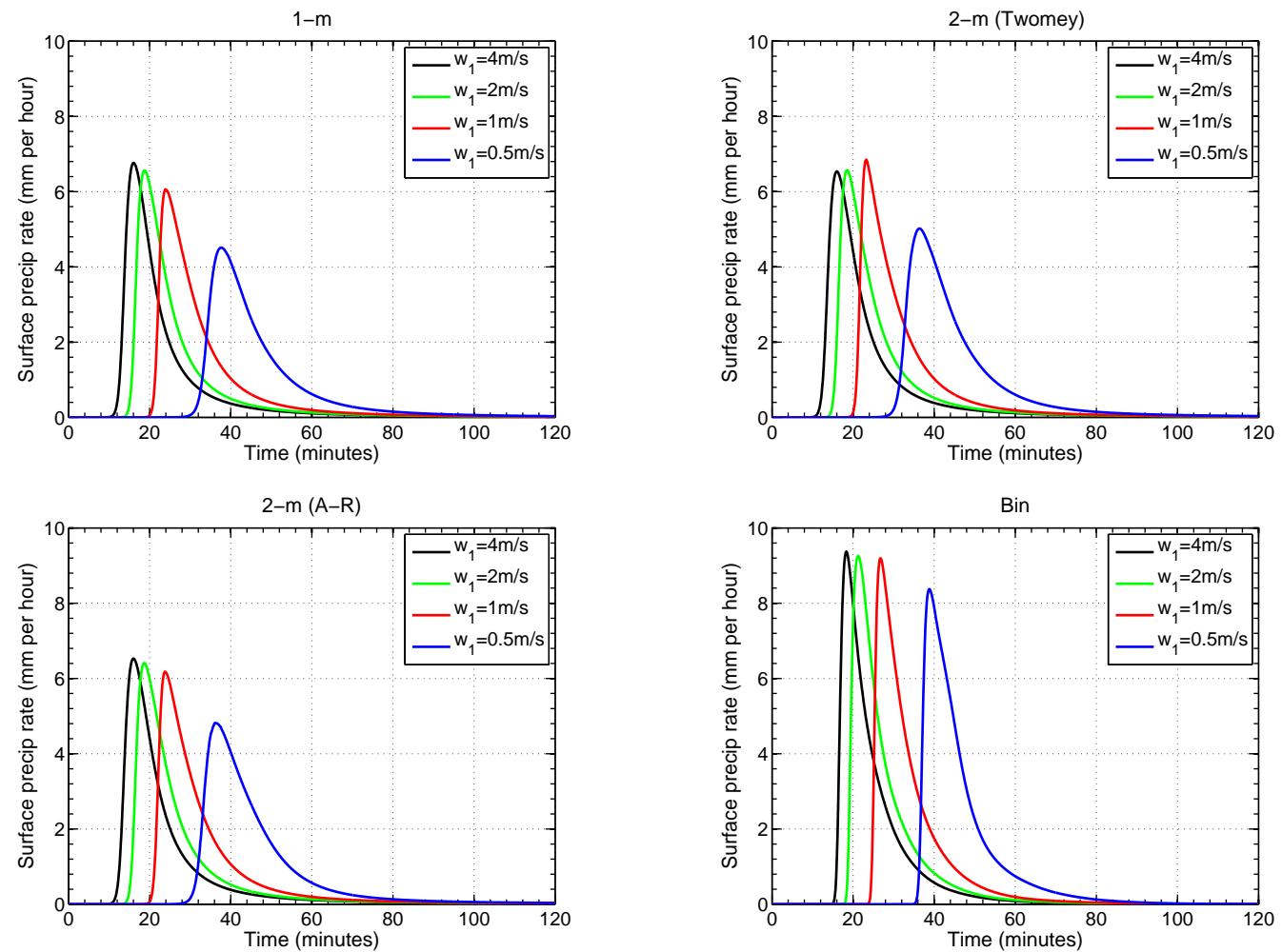

Fig. 7. Timeseries of surface precipitation rates ( $\mathrm{mm} / \mathrm{hr}$ ) from each scheme. Clockwise from top left: 1-m, 2-m Twomey, bin, 2-m A-R. Results are shown with $\mathrm{CCN}=100 / \mathrm{cc}$ and $T=\mathrm{RICO}$, for four different values of $w_{1}$.
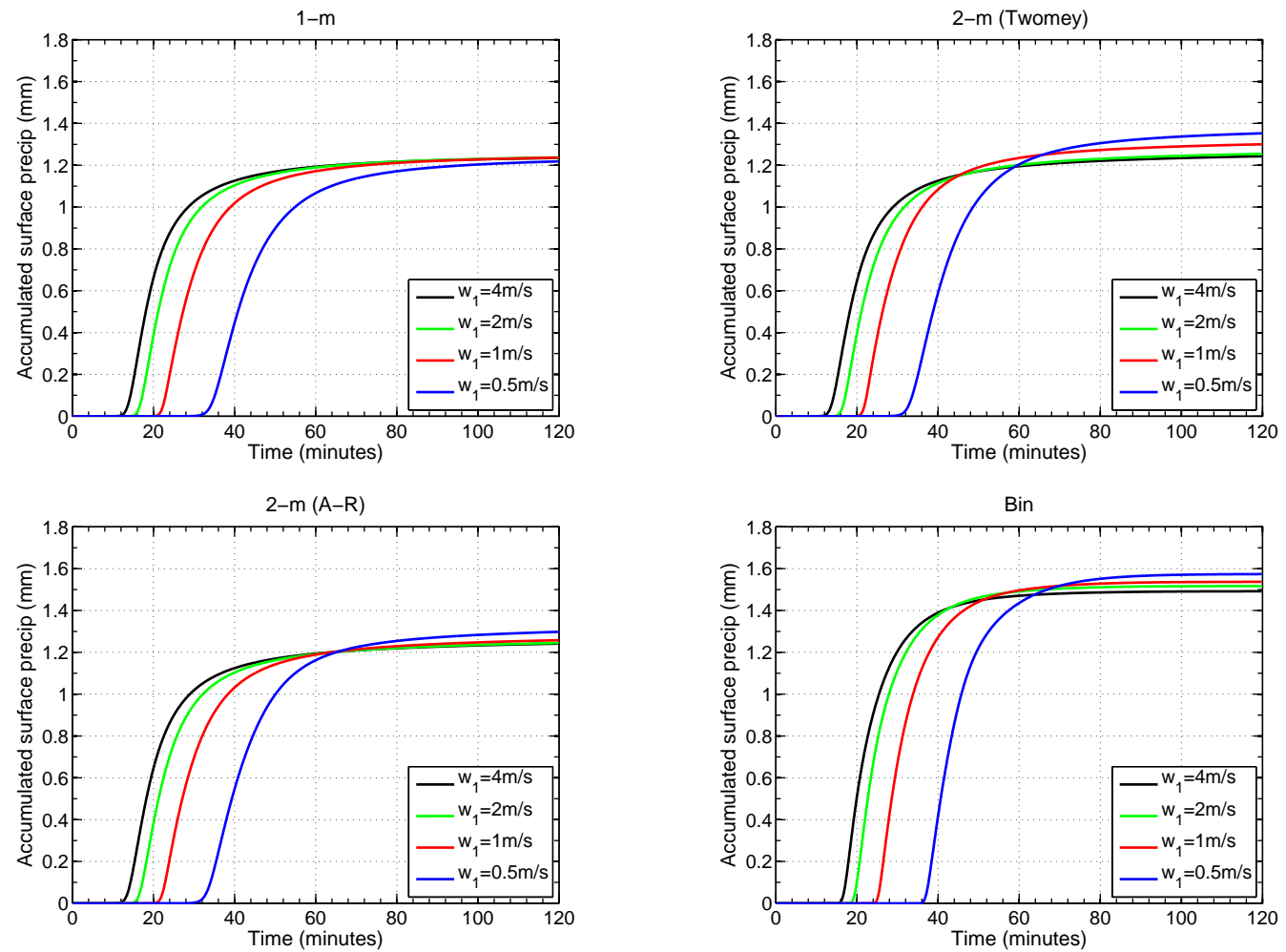

Fig. 8. Timeseries of accumulated surface precipitation ( $\mathrm{mm}$ ) from each scheme. Clockwise from top left: 1-m, 2-m Twomey, bin, 2-m A-R. Results are shown with $\mathrm{CCN}=100 / \mathrm{cc}$ and $T=\mathrm{RICO}$, for four different values of $w_{1}$. 
Table 4. Surface precipitation totals $(\mathrm{mm})$ for each scheme as a function of CCN and $w_{1}$ for three different temperature profiles, namely RICO (top); RICO-2 (middle); and RICO-5 (bottom). Those results highlighted in bold type are plotted in Figs. 7 and 8 as timeseries of surface precipitation rate and accumulated surface precipitation respectively.

\begin{tabular}{|c|c|c|c|c|c|c|c|c|c|c|c|c|}
\hline \multirow{3}{*}{ RICO } & \multicolumn{12}{|c|}{$\mathrm{CCN}$} \\
\hline & \multicolumn{3}{|c|}{$1-\mathrm{m}$} & \multicolumn{3}{|c|}{ 2-m (Twomey) } & \multicolumn{3}{|c|}{ 2-m (A-R) } & \multicolumn{3}{|c|}{ Bin } \\
\hline & $50 / \mathrm{cc}$ & $100 / \mathrm{cc}$ & 200/cc & $50 / \mathrm{cc}$ & $100 / \mathrm{cc}$ & 200/cc & $50 / \mathrm{cc}$ & $100 / \mathrm{cc}$ & 200/cc & $50 / \mathrm{cc}$ & $100 / \mathrm{cc}$ & $200 / \mathrm{cc}$ \\
\hline$w_{1}=0.5 \mathrm{~ms}^{-1}$ & 1.38 & 1.22 & 1.00 & 1.48 & 1.35 & 1.18 & 1.39 & 1.30 & 1.24 & 1.63 & 1.57 & 1.47 \\
\hline$w_{1}=1.0 \mathrm{~ms}^{-1}$ & 1.40 & 1.24 & 1.02 & 1.44 & 1.30 & 1.13 & 1.41 & 1.26 & 1.09 & 1.67 & 1.54 & 1.34 \\
\hline$w_{1}=2.0 \mathrm{~ms}^{-1}$ & 1.40 & 1.24 & 1.02 & 1.41 & 1.25 & 1.08 & 1.41 & 1.25 & 1.04 & 1.67 & 1.52 & 1.27 \\
\hline$w_{1}=4.0 \mathrm{~ms}^{-1}$ & 1.40 & 1.23 & 1.02 & 1.41 & 1.24 & 1.03 & 1.40 & 1.24 & 1.03 & 1.65 & 1.49 & 1.25 \\
\hline \multirow[t]{2}{*}{ RICO-2 } & \multicolumn{3}{|c|}{$1-\mathrm{m}$} & \multicolumn{3}{|c|}{ 2-m (Twomey) } & \multicolumn{3}{|c|}{ 2-m (A-R) } & \multicolumn{3}{|c|}{ Bin } \\
\hline & $50 / \mathrm{cc}$ & $100 / \mathrm{cc}$ & $200 / c c$ & $50 / \mathrm{cc}$ & $100 / \mathrm{cc}$ & $200 / \mathrm{cc}$ & $50 / \mathrm{cc}$ & $100 / \mathrm{cc}$ & $200 / \mathrm{cc}$ & $50 / \mathrm{cc}$ & $100 / \mathrm{cc}$ & $200 / \mathrm{cc}$ \\
\hline$w_{1}=0.5 \mathrm{~ms}^{-1}$ & 1.21 & 1.04 & 0.82 & 1.32 & 1.18 & 1.00 & 1.24 & 1.14 & 1.07 & 1.47 & 1.38 & 1.27 \\
\hline$w_{1}=1.0 \mathrm{~ms}^{-1}$ & 1.23 & 1.06 & 0.84 & 1.27 & 1.13 & 0.96 & 1.25 & 1.08 & 0.91 & 1.48 & 1.34 & 1.13 \\
\hline$w_{1}=2.0 \mathrm{~ms}^{-1}$ & 1.23 & 1.06 & 0.84 & 1.25 & 1.08 & 0.90 & 1.24 & 1.07 & 0.86 & 1.47 & 1.31 & 1.06 \\
\hline$w_{1}=4.0 \mathrm{~ms}^{-1}$ & 1.22 & 1.06 & 0.84 & 1.24 & 1.07 & 0.86 & 1.24 & 1.07 & 0.86 & 1.46 & 1.29 & 1.05 \\
\hline
\end{tabular}

\begin{tabular}{cccc|ccc|ccc|cc|c}
\multirow{2}{*}{ RICO-5 } & \multicolumn{3}{c}{$1-\mathrm{m}$} & \multicolumn{3}{c}{ 2-m (Twomey) } & \multicolumn{3}{c|}{ 2-m (A-R) } & \multicolumn{2}{c}{ Bin } \\
\cline { 2 - 13 } & $50 / \mathrm{cc}$ & $100 / \mathrm{cc}$ & $200 / \mathrm{cc}$ & $50 / \mathrm{cc}$ & $100 / \mathrm{cc}$ & $200 / \mathrm{cc}$ & $50 / \mathrm{cc}$ & $100 / \mathrm{cc}$ & $200 / \mathrm{cc}$ & $50 / \mathrm{cc}$ & $100 / \mathrm{cc}$ & $200 / \mathrm{cc}$ \\
\hline$w_{1}=0.5 \mathrm{~ms}^{-1}$ & 0.97 & 0.80 & 0.58 & 1.08 & 0.93 & 0.76 & 1.02 & 0.90 & 0.82 & 1.22 & 1.12 & 0.99 \\
$w_{1}=1.0 \mathrm{~ms}^{-1}$ & 0.99 & 0.81 & 0.60 & 1.04 & 0.89 & 0.72 & 1.01 & 0.84 & 0.66 & 1.21 & 1.06 & 0.84 \\
$w_{1}=2.0 \mathrm{~ms}^{-1}$ & 0.98 & 0.81 & 0.60 & 1.01 & 0.84 & 0.66 & 1.01 & 0.83 & 0.62 & 1.20 & 1.03 & 0.78 \\
$w_{1}=4.0 \mathrm{~ms}^{-1}$ & 0.98 & 0.81 & 0.60 & 1.01 & 0.83 & 0.62 & 1.00 & 0.83 & 0.61 & 1.18 & 1.01 & 0.76 \\
\hline
\end{tabular}

the bulk and bin schemes, with a slight tendency for the bulk scheme to produce fractionally earlier surface precipitation at lower updraught speeds. There is a relatively large jump in the peak precipitation rates between the 2-m bulk schemes and the bin scheme; consequently the bin scheme produces larger precipitation totals than the bulk schemes as confirmed by Fig. 8. It is interesting to note that in the KiD intercomparison study by Shipway and Hill (2011), the 1-m Morrison scheme was found to overestimate precipitation as validated against the explicit TAU bin model (Tzivion et al., 1987) in the same idealised framework. This is in contrast to the results shown here when comparing the Morrison bulk scheme with ACPIM, suggesting that differences between bin schemes can be as large as those between bulk schemes. A similar conclusion was also reached in the 3-D LES intercomparison of van Zanten et al. (2011), where the spread in precipitation amongst the three bin models considered was found to be as large as the variation between the bulk schemes. A possible explanation for the difference in this particular case is that the TAU-bin model accounts for the coalescence efficiencies of droplets based on the work of Ochs et al. (1986), which acts to reduce the number of suc- cessful collisions involving collector drops in the size range 0.1 to $0.6 \mathrm{~mm}$, whereas the version of ACPIM used in this study assumes a coalescence efficiency of unity for all drop sizes. A detailed investigation into the impact of collection efficiencies on surface precipitation in bin schemes is beyond the scope of this study; however this should be considered in future work to determine the extent to which the choice of collection kernel can account for differences in behaviour between bin schemes.

\subsection{Factorial analysis: quantifying the effects of $\mathrm{CCN}$, $w_{1}$ and $T\left(2^{3}\right.$ design)}

The FM is now used to quantify the sensitivity of the schemes to the choice of microphysical and meteorological factors based on the data provided in Table 4. This section explores the relative importance of each factor as a function of time throughout the evolution of the cloud, and compares the sensitivities of each scheme to illustrate differences in behaviour. Calculation of the relative contributions for each factor and their interactions follows the methodology explained in Dearden (2009). 

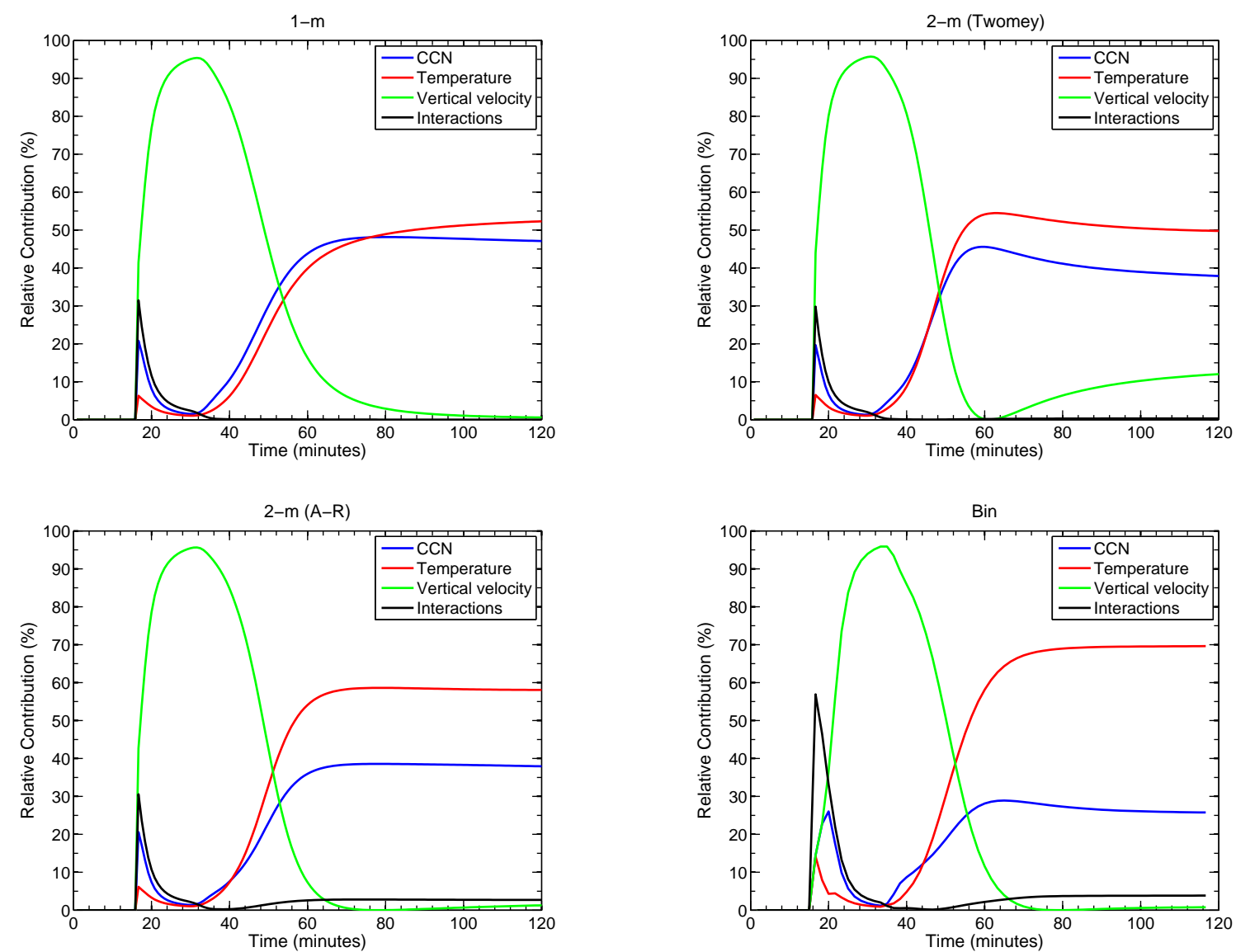

Fig. 9. Relative contribution (\%) timeseries plots for each scheme, considering the effects of changes in CCN, $w_{1}$ and $T$, plus their combined interaction effects. The relative contribution is calculated as a percentage of the total variance associated with the change in precipitation at the surface. The contributions shown are based on the following changes: $w_{1}$ from $0.5 \mathrm{~ms}^{-1}$ to $2 \mathrm{~ms}^{-1}$; CCN from $50 / \mathrm{cc}$ to $100 / \mathrm{cc}$, and $T$ from RICO to RICO-2. Clockwise from top left: 1-m, 2-m Twomey, bin, 2-m A-R.

Figure 9 considers the effect of changes in each factor on the metric of accumulated surface precipitation, and the relative importance of each factor in terms of the enhancement or suppression of surface precipitation is expressed as a percentage of the total variance as a function of time. Specifically, an increase in $w_{1}$ is considered from $0.5 \mathrm{~ms}^{-1}$ to $2 \mathrm{~ms}^{-1}$, along with a cooling of the temperature profile, $T$, from RICO to RICO-2, and an increase in CCN from 50/cc to $100 / \mathrm{cc}$. Figure 9 shows that, in all four schemes, the change in precipitation is dominated by the change in vertical velocity in the early stages of cloud development. Beyond 40 minutes, the relative importance of the vertical velocity effect reduces and by the end of the simulations, the change in temperature produces the largest effect on the suppression of precipitation. However the schemes disagree on the extent of the relative importance of the $\mathrm{CCN}$ and temperature effects. It can be seen in Fig. 9 that the contribution of the CCN effect is largest in the 1-m scheme; this is a consequence of the experimental setup for the 1-m scheme where an assumption is made that the change in droplet number is equal to the change in $\mathrm{CCN}$ concentration, independent of the change in vertical velocity. For the $2-\mathrm{m}$ bulk schemes, the contribution of the CCN effect is slightly reduced; this can be explained as follows. For slowly increasing updraught speeds such as the $0.5 \mathrm{~ms}^{-1}$ case, the ability to predict droplet number results in competition for water vapour between growth of existing droplets and activation of new droplets; this is demonstrated by Dearden (2009) using a simple lagrangian parcel model. The presence of $\mathrm{CCN}$ that activate at relatively low updraught speeds act as a sink of water vapour through growth by condensation, resulting in fewer droplets being activated overall compared to the 1-m scheme where by design the droplet number concentrations are slightly higher. This explains why the $1-\mathrm{m}$ scheme has the largest relative contribution from the effect of $\mathrm{CCN}$ according to Fig. 9. However the 2-m A-R scheme, which includes a parameterization for the maximum supersaturation based on the vertical velocity and the properties of the aerosol size distribution, shows less of a change in droplet number at low updraught speeds and therefore less of an impact on precipitation. Consequently 

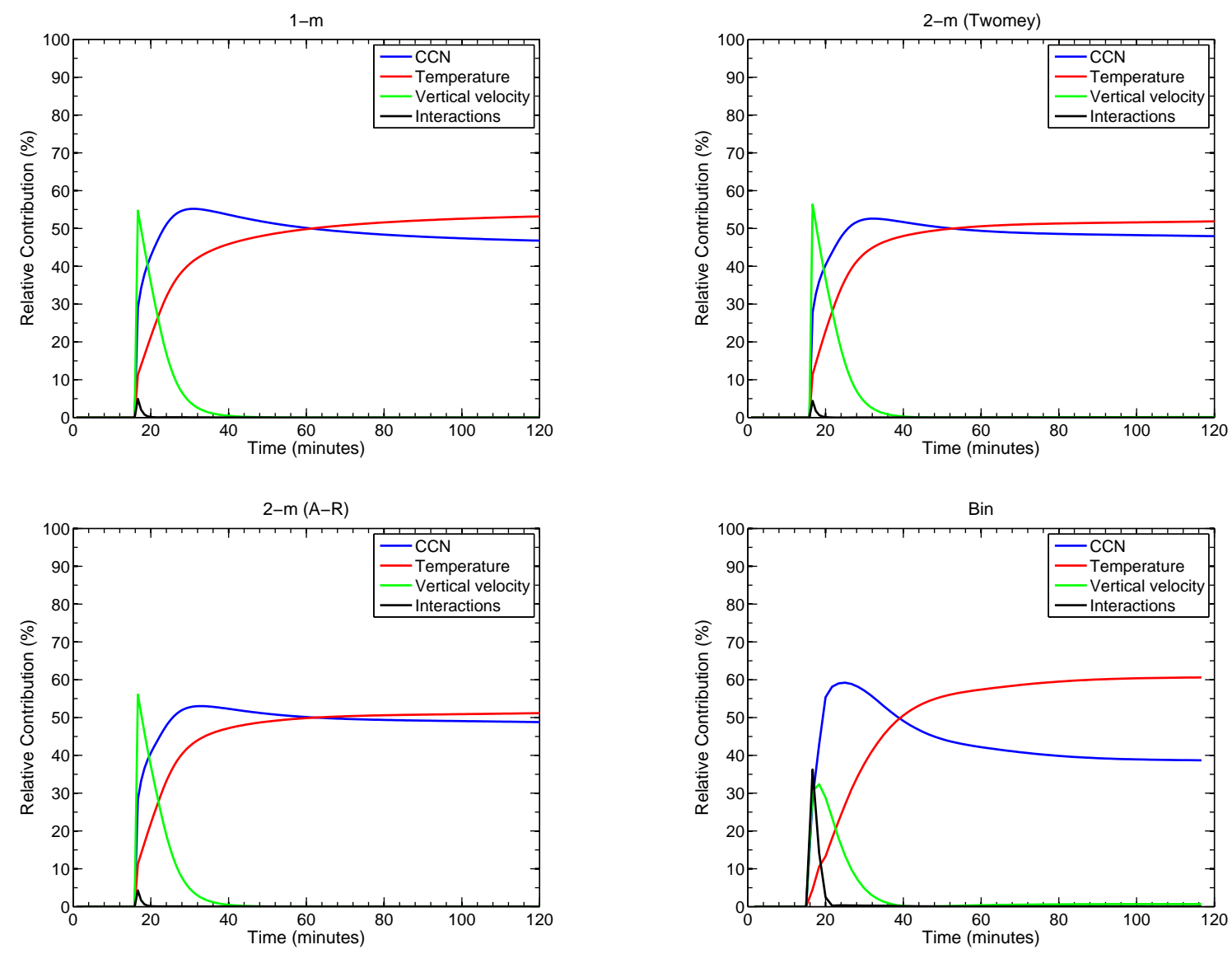

Fig. 10. As for Fig. 9 but for an increase in $w_{1}$ from $2 \mathrm{~ms}^{-1}$ to $4 \mathrm{~ms}^{-1}$.

Fig. 9 shows that the 2-m A-R scheme improves the comparison with the bin scheme. However in more rapidly increasing updraughts, Fig. 10 shows that the benefit of predicting droplet number concentration is lost and the 2-m A$\mathrm{R}$ scheme produces largely the same sensitivity as the $1-\mathrm{m}$ scheme. This is a consequence of the fact that, towards larger vertical velocities, the droplet number concentrations converge in the bulk schemes, thus producing very similar sensitivities. Some additional simulations with the 1-m scheme were also performed where the assumed droplet concentration at low updraught speeds was set to a value more representative of the predicted values from the 2-m A-R scheme. The results from these tests (not shown) reveal that tuning the droplet number concentration in the 1-m scheme allows the total precipitation values to match those produced by the 2-m A-R scheme, whilst also improving the agreement in terms of the relative contributions. This result suggests that a diagnostic representation of droplet number based on $\mathrm{CCN}$ number and updraught velocity would be sufficient to capture aerosol indirect effects for the chosen scenario. This has important implications when considering the balance between model complexity and computational efficiency, as it shows that in the absence of feedbacks at least, a prognostic variable for droplet number may not be necessary, and that a diagnostic treatment of droplet number could help to minimise the cost of the scheme without compromising the ability of the model to capture the effects of aerosol.

The remaining difference in sensitivities between the bin and 2-m A-R bulk scheme as shown in Figs. 9 and 10 can be explained by considering the effects of evaporation below cloud base. It has already been shown that the rain mass falling out of the cloud in the bin scheme is greater than in the bulk schemes (Fig. 4), but also that the bin scheme produces consistently larger amounts of surface precipitation. It is hypothesised that differences in collection efficiencies between the bulk and bin schemes are contributing to the different sensitivities to temperature and $\mathrm{CCN}$, and specifically that larger rain drop sizes in the bin scheme are leading to an overall reduction in rain evaporation. To explore this hypothesis, a sensitivity test was performed with the 2-m A-R scheme where the rain fall speed parameter $b_{r}$ is increased from the default value of 0.8 to 0.825 to facilitate larger rain drops, in order to test the impact on evaporation and the amount of rain that reaches the surface. Table 5 shows that the modification to the fallspeeds for rain in the bulk scheme leads to an increase in accretion, a reduction in rain evaporation, and in 
Table 5. Rain evaporation $\left(\mathrm{kgm}^{-2}\right.$; top), accretion $\left(\mathrm{kgm}^{-2}\right.$; middle) and surface precipitation ( $\mathrm{mm}$; bottom) accumulated over $2 \mathrm{~h}$ from the 2-m A-R scheme, as a function of CCN, $w_{1}$ and $T$, and also from the 2-m A-R scheme with increased fallspeed parameter for rain, such that $b_{r}=0.825$. The evaporation and accretion terms are calculated by integrating the process rates with height at each timestep, and then integrating these values in time over a $2 \mathrm{~h}$ period.

\begin{tabular}{ccccc|cccc}
\hline & \multicolumn{4}{c|}{$\mathrm{RICO}$} & \multicolumn{4}{c}{$\mathrm{RICO}-2$} \\
\cline { 2 - 8 }$w_{1}$ & \multicolumn{2}{c}{$2-\mathrm{m} \mathrm{A-R}$} & \multicolumn{2}{c|}{$2-\mathrm{m} \mathrm{A-R}\left(b_{r}=0.825\right)$} & \multicolumn{2}{c}{$2-\mathrm{m} \mathrm{A-R}$} & \multicolumn{2}{c}{$2-\mathrm{m} \mathrm{A-R}\left(b_{r}=0.825\right)$} \\
& $50 / \mathrm{cc}$ & $100 / \mathrm{cc}$ & $50 / \mathrm{cc}$ & $100 / \mathrm{cc}$ & $50 / \mathrm{cc}$ & $100 / \mathrm{cc}$ & $50 / \mathrm{cc}$ & $100 / \mathrm{cc}$ \\
\hline $0.5 \mathrm{~ms}^{-1}$ & 0.48 & 0.45 & 0.41 & 0.39 & 0.44 & 0.41 & 0.38 & 0.35 \\
$1.0 \mathrm{~ms}^{-1}$ & 0.43 & 0.41 & 0.37 & 0.35 & 0.41 & 0.39 & 0.35 & 0.33 \\
$2.0 \mathrm{~ms}^{-1}$ & 0.44 & 0.42 & 0.37 & 0.36 & 0.42 & 0.40 & 0.35 & 0.34 \\
$4.0 \mathrm{~ms}^{-1}$ & 0.45 & 0.43 & 0.38 & 0.36 & 0.43 & 0.41 & 0.36 & 0.35 \\
\hline
\end{tabular}

\begin{tabular}{ccccc|cccc} 
& \multicolumn{4}{c}{$\mathrm{RICO}$} & \multicolumn{3}{c}{$\mathrm{RICO}-2$} \\
\cline { 2 - 8 }$w_{1}$ & \multicolumn{2}{c}{$2-\mathrm{m} \mathrm{A-R}$} & \multicolumn{2}{c}{$2-\mathrm{m} \mathrm{A}-\mathrm{R}\left(b_{r}=0.825\right)$} & \multicolumn{2}{c}{$2-\mathrm{m} \mathrm{A}-\mathrm{R}$} & \multicolumn{2}{c}{$2-\mathrm{m} \mathrm{A-R}\left(b_{r}=0.825\right)$} \\
& $50 / \mathrm{cc}$ & $100 / \mathrm{cc}$ & $50 / \mathrm{cc}$ & $100 / \mathrm{cc}$ & $50 / \mathrm{cc}$ & $100 / \mathrm{cc}$ & $50 / \mathrm{cc}$ & $100 / \mathrm{cc}$ \\
\hline $0.5 \mathrm{~ms}^{-1}$ & 1.58 & 1.57 & 1.64 & 1.63 & 1.41 & 1.40 & 1.47 & 1.46 \\
$1.0 \mathrm{~ms}^{-1}$ & 1.60 & 1.55 & 1.65 & 1.62 & 1.43 & 1.37 & 1.48 & 1.44 \\
$2.0 \mathrm{~ms}^{-1}$ & 1.60 & 1.55 & 1.65 & 1.62 & 1.43 & 1.36 & 1.48 & 1.43 \\
$4.0 \mathrm{~ms}^{-1}$ & 1.58 & 1.54 & 1.63 & 1.61 & 1.42 & 1.36 & 1.47 & 1.43 \\
\hline
\end{tabular}

\begin{tabular}{ccccc|cccc} 
& \multicolumn{4}{c}{$\mathrm{RICO}$} & \multicolumn{4}{c}{$\mathrm{RICO}-2$} \\
\cline { 2 - 9 }$w_{1}$ & \multicolumn{2}{c}{$2-\mathrm{m} \mathrm{A-R}$} & \multicolumn{2}{c}{$2-\mathrm{m} \mathrm{A}-\mathrm{R}\left(b_{r}=0.825\right)$} & \multicolumn{2}{c}{$2-\mathrm{m}$ A-R } & \multicolumn{2}{c}{$2-\mathrm{m} \mathrm{A-R}\left(b_{r}=0.825\right)$} \\
& $50 / \mathrm{cc}$ & $100 / \mathrm{cc}$ & $50 / \mathrm{cc}$ & $100 / \mathrm{cc}$ & $50 / \mathrm{cc}$ & $100 / \mathrm{cc}$ & $50 / \mathrm{cc}$ & $100 / \mathrm{cc}$ \\
\hline $0.5 \mathrm{~ms}^{-1}$ & 1.39 & 1.30 & 1.49 & 1.41 & 1.24 & 1.14 & 1.33 & 1.25 \\
$1.0 \mathrm{~ms}^{-1}$ & 1.41 & 1.26 & 1.51 & 1.38 & 1.25 & 1.08 & 1.34 & 1.21 \\
$2.0 \mathrm{~ms}^{-1}$ & 1.41 & 1.25 & 1.51 & 1.38 & 1.24 & 1.07 & 1.34 & 1.20 \\
$4.0 \mathrm{~ms}^{-1}$ & 1.40 & 1.24 & 1.51 & 1.37 & 1.24 & 1.07 & 1.34 & 1.20 \\
\hline
\end{tabular}

turn an increase in the total surface precipitation. Figure 11 shows the effect of this change on the relative contributions in the bulk scheme, and illustrates how the effect of $\mathrm{CCN}$ is reduced at the expense of the effect of temperature in accordance with the bin scheme. However it is also recognised that differences in the numerical treatment of sedimentation between the bin and bulk schemes (as discussed in Sect. 2.3.1) may be contributing to the difference in sensitivities as well. To explore this further, extra tests were performed with the bulk scheme where the existing first-order treatment of sedimentation was circumvented and replaced with increasingly higher order forward-difference approximations as specified in Jacobson (2005, p. 180), up to and including a fourthorder scheme for consistency with the bin model. Results from these tests (not shown) reveal that increasing the order of approximation from first to second order leads to a small increase in total surface precipitation (around $5 \%$ ) over the range of bulk simulations considered. Subsequent increases to third and fourth order accuracy were found to have negligible impact on precipitation. These results suggest that the use of a lower order treatment of sedimentation in the bulk scheme does not contribute significantly to the differences shown when comparing against the bin scheme.

\subsection{Factorial analysis: the effect of increasing vertical velocity for a fixed temperature $\left(2^{2}\right.$ design $)$}

It is now prudent to explore the sensitivity of surface precipitation to different levels of change in the vertical velocity field. The sensitivities of each scheme can be compared through consideration of the total effect on precipitation suppression, as described in Sect. 3.2; the sign and magnitude of the result indicates the direction and significance of the induced change. In this case the factors considered are $\mathrm{CCN}$ and $w_{1}$, with a fixed background temperature and humidity based on the RICO profile, yielding a $2^{2}$ design. The results from the following FM analysis are based on values of surface precipitation accumulated at the end of the model simulation. Following the logic from Sect. 3.2, the $2^{2}$ design has 


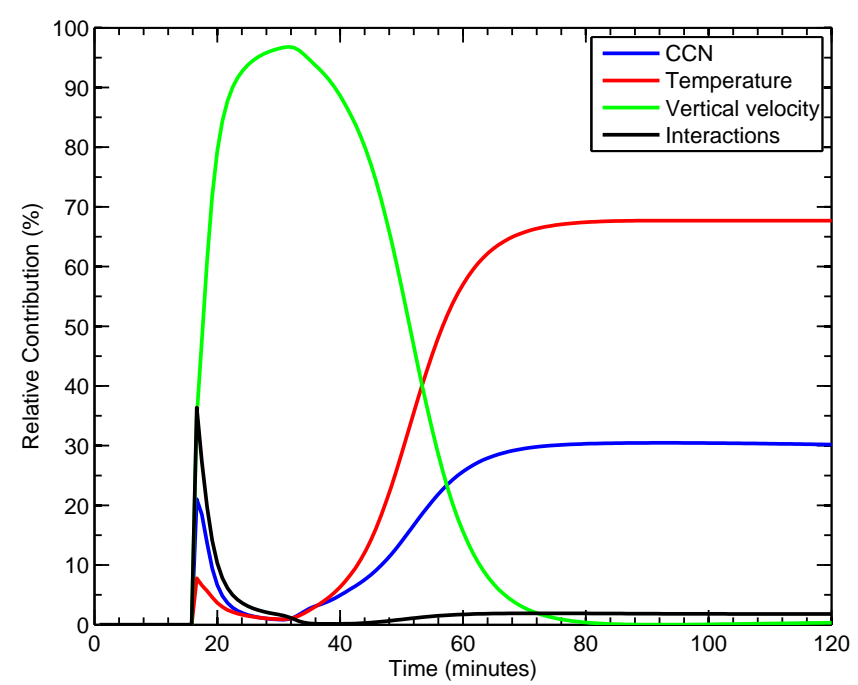

Fig. 11. As Fig. 9 but for the 2-m A-R scheme with modified fallspeed parameter for rain, such that $b_{r}$ is increased from the default value of 0.8 to 0.825 . All other fallspeed parameters are unchanged.

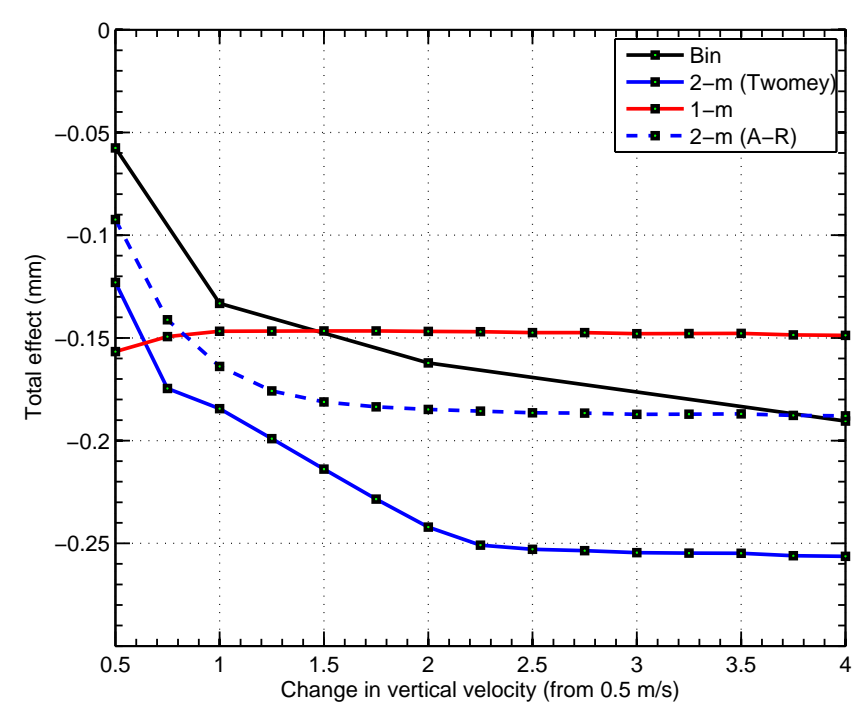

Fig. 12. Total effect on suppression of precipitation (in $\mathrm{mm}$ ) from each scheme as a function of changes in $w_{1}$ and $\mathrm{CCN}$, under a fixed temperature ( $T=\mathrm{RICO})$. Changes in $w_{1}$ are considered from $0.5 \mathrm{~ms}^{-1}$ up to $4 \mathrm{~ms}^{-1}$, and the change in CCN is from $50 / \mathrm{cc}$ to $100 / \mathrm{cc}$.

three degrees of freedom, such that the total effect is equal to the sum of the effects of the two main factors plus their interaction.

Figure 12 considers the total effect on precipitation resulting from repeated increases in $w_{1}$ from a low value of $0.5 \mathrm{~ms}^{-1}$, plus the additional effect of an increase in $\mathrm{CCN}$ from 50/cc to 100/cc. For the 1-m scheme, Fig. 12 illustrates that the reduction in precipitation is due solely to the change in droplet number and is essentially insensitive to changes in updraught speed, which is clearly a limitation when comparing against the bin scheme (solid black line) under the same conditions. In theory the sensitivity of the 1-m scheme to vertical velocity could be increased by using a diagnostic relationship for droplet number concentration instead of the assumption of a fixed value as used in this study. Both 2$\mathrm{m}$ schemes show an increase in suppression of rainfall as a function of increasing vertical velocity, which in a qualitative sense agrees with the bin scheme. However the 2-m Twomey scheme considerably overestimates the amount by which precipitation is suppressed. This can be understood by considering the total precipitation for the 50/cc case from Table 4. The 2-m Twomey scheme produces relatively more precipitation than the other schemes at low updraught speeds, suggesting that it activates fewer droplets at 50/cc. Thus when the value of $\mathrm{CCN}$ is increased to $100 / \mathrm{cc}$, the suppression of precipitation appears to be exaggerated. The implications of this are that for this idealised case, a single value of $k$ for different $\mathrm{CCN}$ concentrations is not appropriate, and that the value of $k$ should change as a function of the assumed CCN concentration. This problem is alleviated in the 2-m A-R scheme, where knowledge of the aerosol composition and log-normal size distribution is advantageous in obtaining a better agreement with the bin scheme.

For values of $w_{1}$ starting from $2 \mathrm{~ms}^{-1}$ (as shown in Fig. 13), all four schemes are in much better agreement in terms of the overall amount by which precipitation is suppressed. Thus it is difficult to justify the increased computational expense of a 2-m liquid scheme in this regime when a $1-\mathrm{m}$ scheme performs in such a similar manner.

\section{Summary and discussion}

The Factorial Method has been used to compare the sensitivities of warm shallow cumulus cloud as simulated by four different microphysics schemes of increasing levels of complexity using an idealised 1-D column framework. The use of a simple driver model is intended to aid the comparison by removing the sensitivity to dynamical feedbacks, thus isolating the pure microphysical behaviour. The chosen factors include the magnitude of the cloud base vertical velocity, the ambient temperature profile, and the assumed number of aerosol available to act as CCN. The sensitivity of each scheme was assessed and quantified in terms of the suppression of precipitation at the surface, with the bin scheme used as a benchmark in order to validate the performance of the bulk schemes.

The reader is reminded that all of the results found in this study are specific to the particular test case in question, and future work will be necessary using the tools presented in this paper to determine the generality of our results. For the idealised case considered in this study where feedback effects are neglected, the performance of the bulk schemes for cloud 


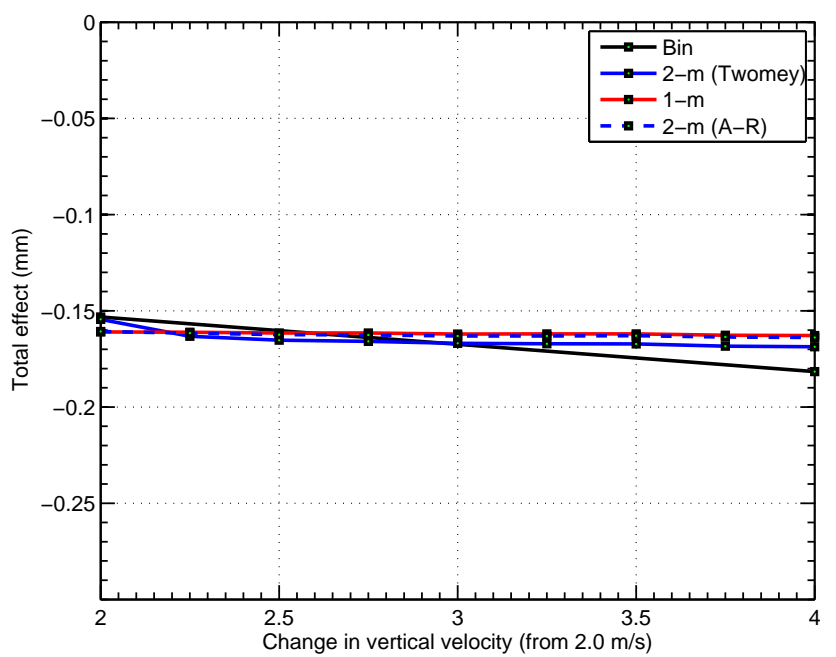

Fig. 13. As Fig. 12 but for changes in $w_{1}$ starting from $2 \mathrm{~ms}^{-1}$.

base updraught speeds up to $2 \mathrm{~ms}^{-1}$ was found to depend on the assumptions made with regards the method of droplet activation. At updraughts larger than $2 \mathrm{~ms}^{-1}$, all schemes activate most if not all of the available $\mathrm{CCN}$ and so essentially reduce to the same droplet number concentrations. In this regime the 2-m bulk schemes were found to behave much like the 1-m bulk scheme. This suggests that for models with sufficient resolution, it is theoretically possible to optimise the balance between complexity and cost by allowing the model to choose the appropriate level of microphysical detail based on the magnitude of the cloud base updraught speed and knowledge of microphysical parameters such as aerosol number concentration and size. This stresses the importance of coupling the microphysics to a prognostic aerosol scheme to provide the necessary information. It should also be noted that it was possible to tune the 1-m scheme at low updraught speeds to produce essentially the same precipitation amounts and sensitivities as the 2-m scheme, by fixing the assumed droplet number concentration to match those of the predicted concentrations. This suggests that in the absence of feedbacks, a diagnostic relationship for droplet number may perform just as well as a prognostic treatment. This has obvious advantages in terms of computational efficiency given that one less prognostic variable would need to be advected.

Further comparison of the schemes also highlighted some fundamental differences in behaviour worthy of comment. For instance the bin scheme consistently produced larger amounts of precipitation when compared to the bulk schemes, even in scenarios where all schemes produced very similar droplet number concentrations. A cooling of the temperature profile by $2{ }^{\circ} \mathrm{C}$ under a fixed relative humidity was also found to produce a relatively higher contribution to precipitation suppression in the bin scheme compared to the bulk schemes. It was possible to enhance the dominance of the temperature effect in the bulk scheme and thus im- prove the agreement with the bin scheme by modifiying the fallspeed parameters for rain, which served to increase accretion, reduce evaporation and thus increase the surface precipitation. Differences in evaporation of rain between schemes may have important consequences in terms of dynamical feedbacks in full 3-D simulations, by modifying the extent of evaporative cooling of the sub-cloud layer. A consideration of such feedbacks is beyond the scope of this paper, but warrants further invesigation in future work.

It is important to note that separate intercomparison studies comparing bin and bulk schemes using the KiD framework do not necessarily support the conclusion that bin schemes produce more precipiation than bulk schemes. Thus the enhanced sensitivity to temperature as seen in the ACPIM bin model may not be a general feature of bin schemes. Although it was shown that the bulk scheme could be effectively tuned to produce better agreement with this particular bin scheme, the same tuning may not necessarily improve the agreement relative to other bin schemes. Future work should therefore focus on investigating and understanding the origin of differences between bin schemes to increase confidence in their use as benchmarks against which simpler bulk parameterizations are validated. Suggested variables for investigation include the number of size bins used to resolve the liquid size distribution, the treatment of aerosol (whether a fixed log-normal mode or prognostic), the choice of collection kernel and the numerical treatment of advection. In light of these potential sources of differences, the need to constrain bin schemes with field observations and laboratory experiments is also recognised.

A big caveat in producing these conclusions is the absence of entrainment and feedback effects in the 1-D framework. The 1-D framework does not account for entrainment mixing within the cloud, and in reality, the effect of entrainment mixing could to some extent counteract the change in temperature due to vertical advection. There is a growing suggestion within the available literature that the inclusion of feedback effects is likely to dampen the sensitivity of warm clouds to increases in aerosol loadings. For instance, the study by Jiang et al. (2006) used a 3-D LES modelling approach to compare the lifetime of polluted cumulus clouds to those of clean cumulus clouds when entrainment is allowed to occur. The results suggest the overall lifetime of both the polluted and clean clouds are statistically similar, and propose an evaporation-entrainment feedback mechanism which acts to dilute polluted clouds (i.e. reduce liquid water content) and therefore reduce the overall sensitivity of warm shallow cumuli to changes in aerosol concentration. Stevens and Feingold (2009) also argue that in reality, the sensitivity of clouds and precipitation to changes in aerosol concentration is on average weaker than a purely microphysical consideration alone would suggest, due to the capacity of the system to respond differentially to changes in aerosol, thereby acting to buffer the global system against such changes and reducing the overall effect. Stevens and Seifert (2008) even suggest 
that the effect of increased aerosol loadings on shallow convection could in some instances lead to an enhancement of precipitation, since the delay in the onset of rain formation may allow the cloud to achieve a greater depth and therefore a higher liquid water path. Therefore the results of this study should be considered only as a starting point, with the recommendation that the techniques of factor separation be utilised in future work to help quantify the extent to which the sensitivities shown in this paper are modified within a more realistic dynamical framework.

\section{Appendix A}

\section{Method of moment-conserving fits}

Diagnosis of the shape parameter for in the ACPIM model is based on the following methodology, which fits the resolved liquid size distribution for drop diameters greater than $50 \mathrm{mi}-$ crons to a gamma function.

In general, the $k$-th moment of a size distribution $n(D)$ is specified as:

$M_{k}=\int_{0}^{\infty} D^{k} n(D) d D$

where in this case $n(D)$ is based on a gamma distribution as in Eq. (1). The $k$-th moment of a gamma distribution can be expressed analytically, and is given by:

$M_{k}=N_{0} \frac{\Gamma(\mu+k+1)}{\lambda^{\mu+k+1}}$

Consequently the zeroth, first and second moments of a gamma distribution are written as follows:

$$
\begin{aligned}
M_{0} & =N_{0} \frac{\Gamma(\mu+1)}{\lambda^{\mu+1}} \\
M_{1} & =N_{0} \frac{\Gamma(\mu+2)}{\lambda^{\mu+2}} \\
M_{2} & =N_{0} \frac{\Gamma(\mu+3)}{\lambda^{\mu+3}}
\end{aligned}
$$

The quantity $F$ is now introduced and defined as the square of the first moment divided by the product of the second and zeroth moments:

$F=\frac{M_{1}^{2}}{M_{2} M_{0}}=\frac{\Gamma(\mu+2)^{2}}{\Gamma(\mu+1) \Gamma(\mu+3)}$

Using the following property of gamma functions,

$\Gamma(\mu)=(\mu-1) \Gamma(\mu-1)$

it is possible to re-write the expression for $F$ as follows:

$$
F=\frac{(\mu+1)^{2} \Gamma(\mu+1)^{2}}{\Gamma(\mu+1)(\mu+2)(\mu+1) \Gamma(\mu+1)}=\frac{\mu+1}{\mu+2}
$$

Rearranging Eq. (A6) in terms of $\mu$ gives:

$\mu=\frac{1-2 F}{F-1}$

Equation (A7) is used to calculate the shape parameter $\mu$, where the quantity $F$ is obtained from the model microphysics based on explicit calculation of the moments of the resolved size distribution given by $M_{k}=\sum_{i=1}^{m} N_{i} D_{i}^{k}$, where $N_{i}$ and $D_{i}$ are the number concentration and diameter respectively for size category $i$, and $m$ is the total number of size bins. Rain was diagnosed in the bin scheme using a diameter thresold of 50 microns for consistency with the bulk autoconversion scheme.

Acknowledgements. The first author would like to thank Ben Shipway and Adrian Hill of the Met Office for their advice and feedback in setting up the KiD model. Thanks also to Hugh Morrison of NCAR, USA for supplying the latest version of the bulk microphysics code used in this study, and to the three anonymous reviewers whose comments helped to improve the final manuscript.

Edited by: B. Stevens

\section{References}

Abdul-Razzak, H., Ghan, S. J., and Rivera-Carpio, C.: A parameterization of aerosol activation - 1. Single aerosol type, J. Geophys. Res.-Atmos., 103, 6123-6131, 1998.

Abel, S. J. and Shipway, B. J.: A comparison of cloud-resolving model simulations of trade wind cumulus with aircraft observations taken during RICO, Q. J. Roy. Meteor. Soc., 133, 781-794, 2007.

Albrecht, B. A.: Aerosols, cloud microphysics, and fractional cloudiness, Science, 245, 1227-1230, 1989.

Bony, S. and Dufresne, J. L.: Marine boundary layer clouds at the heart of tropical cloud feedback uncertainties in climate models, Geophys. Res. Lett., 32, L20806, doi:10.1029/2005GL023851, 2005.

Bott, A.: A positive definite advection scheme obtained by nonlinear renormalization of the advective fluxes, Mon. Weather Rev., 117, 1006-1015, 1989.

Bott, A.: Monotone flux limitation in the area-preserving flux-form advection algorithm, Mon. Weather Rev., 120, 2592-2602, 1992.

Bott, A.: A flux method for the numerical solution of the stochastic collection equation: Extension to two-dimensional particle distributions, J. Atmos. Sci., 57, 284-294, 2000.

Dearden, C.: Investigating the simulation of cloud microphysical processes in numerical models using a one-dimensional dynamical framework, Atmos. Sci. Lett., 10, 207-214, 2009.

Hall, W. D.: A detailed microphysical model within a twodimensional dynamic framework - Model description and preliminary-results, J. Atmos. Sci., 37, 2486-2507, 1980.

Heymsfield, A. and McFarquhar, G.: Microphysics of INDOEX clean and polluted trade cumulus clouds, J. Geophys. Res.Atmos., 106, 28653-28673, 2001.

IPCC: Climate Change 2007 - The Physical Science Basis: Contribution of Working Group I to the Fourth Assessment Report of the IPCC, Cambridge University Press., 2007. 
Jacobson, M. Z.: Fundamentals of Atmospheric Modeling 2nd edition, Cambridge University Press., 2005.

Jiang, H., Huiwen, X., Teller, A., Feingold, G., and Levin, Z.: Aerosol effects on the lifetime of shallow cumulus, Geophys. Res. Lett., 33, L14806, doi:10.1029/2006GL026024, 2006.

Khairoutdinov, M. and Kogan, Y.: A new cloud physics parameterization in a large-eddy simulation model of marine stratocumulus, Mon. Weather Rev., 128, 229-243, 2000.

Laaksonen, A., Vesala, T., Kulmala, M., Winkler, P. M., and Wagner, P. E.: Commentary on cloud modelling and the mass accommodation coefficient of water, Atmos. Chem. Phys., 5, 461-464, doi:10.5194/acp-5-461-2005, 2005.

Leonard, B. P., MacVean, M. K., and Lock, A. P.: Positivitypreserving numerical schemes for multidimensional advection, NASA Technical Memorandum, 1993.

Liu, J. Y. and Orville, H. D.: Numerical modelling of precipitation and cloud shadow effects on mountain-induced cumuli, J. Atmos. Sci., 26, 1283-1298, 1969.

Marshall, J. S. and Palmer, M. K.: The distribution of raindrops with size. J. Meteor., 5, 165-166, 1948.

Medeiros, B. and Stevens, B.: Revealing differences in GCM representations of low clouds. Clim. Dyn., 36, 385-399, doi:10.1007/s00382-009-0694-5, 2010.

Milbrandt, J. A. and McTaggart-Cowan, R.: Sedimentation-Induced Errors in Bulk Microphysics Schemes, J. Atmos. Sci., 67, 39313948, 2010.

Morrison, H., Curry, J. A., and Khvorostyanov, V. I.: A new doublemoment microphysics parameterization for application in cloud and climate models. Part I: Description, J. Atmos. Sci., 62, 1665$1677,2005$.

Morrison, H. and Grabowski, W. W.: Comparison of bulk and bin warm-rain microphysics models using a kinematic framework, J. Atmos. Sci., 64, 2839-2861, 2007.

Morrison, H., Thompson, G., and Tatarskii, V.: Impact of Cloud Microphysics on the Development of Trailing Stratiform Precipitation in a Simulated Squall Line: Comparison of One- and TwoMoment Schemes, Mon. Weather Rev., 137, 991-1007, 2009.

Nuijens, L., Stevens, B. and Siebesma, A. P.: The environment of precipitating shallow convection, J. Atmos. Sci., 66, 1962-1979, 2009.

Ochs, H. T., Czys, R. R., and Beard, K. V.: Laboratory measurements of coalescence efficiencies for small precipitating drops, J. Atmos. Sci., 43, 225-232, 1986.

Press, W. H., Teukolsky, S. A., Vetterling, W. T., and Flannery, B. P.: Numerical Recipes 3rd edition: The Art of Scientific Computing, Cambridge University Press., 2007.

Pruppacher, H. R. and Klett, J. D.: Microphysics of Clouds and Precipitation, Kluwer Academic Publishers., 1997.

Rauber, R. M., Stevens, B., Ochs, III, H. T., Knight, C., Albrecht, B. A., Blyth, A. M., Fairall, C. W., Jensen, J. B., Lasher-Trapp, S. G., Mayol-Bracero, O. L., Vali, G., Anderson, J. R., Baker, B. A., Bandy, A. R., Burnet, E., Brenguier, J. L., Brewer, W. A., Brown, P. R. A., Chuang, P., Cotton, W. R., Girolamo, L. D., Geerts, B., Gerber, H., Goke, S., Gomes, L., Heikes, B. G., Hudson, J. G., Kollias, P., Lawson, R. P., Krueger, S. K., Lenschow, D. H., Nuijens, L., O'Sullivan, D. W., Rilling, R. A., Rogers, D. C., Siebesma, A. P., Snodgrass, E., Stith, J. L., Thornton, D. C., Tucker, S., Twohy, C. H., and Zuidema, P.: Rain in shallow cumulus over the ocean - The RICO campaign, B. Am. Meteo- rol. Soc., 88, 1912, doi:10.1175/BAMS-88-12-1912, 2007.

Rogers, R. R. and Yau, M. K.: A Short Course in Cloud Physics, 3rd edition, Butterworth and Heinemann, 1989.

Seifert, A.: On the Parameterization of Evaporation of Raindrops as Simulated by a One-Dimensional Rainshaft Model. J. Atmos. Sci., 65, 3608-3619, 2008.

Seifert, A. and Beheng, K. D.: A double-moment parameterization for simulating autoconversion, accretion and selfcollection, Atmos. Res., 59, 265-281, 2001.

Seifert, A. and Stevens, B.: Microphysical Scaling Relations in a Kinematic Model of Isolated Shallow Cumulus Clouds, J. Atmos. Sci., 67, 1575-1590, 2010.

Shipway, B. J. and Hill, A. A.: A 1D modelling framework for a microphysics intercomparison study: Part I, Q. J. Roy. Meteor. Soc., submitted, 2011.

Stein, U. and Alpert, P.: Factor Separation in Numerical Simulations, J. Atmos. Sci., 50, 2107-2115, 1993.

Stevens, B. and Feingold, G.: Untangling aerosol effects on clouds and precipitation in a buffered system, Nature, 461, 607-613, 2009.

Stevens, B. and Seifert, A.: Understanding macrophysical outcomes of microphysical choices in simulations of shallow cumulus convection, J. Meteorol. Soc. Japan, 86A, 143-162, 2008.

Straka, J. M.: Cloud and Precipitation Microphysics, Cambridge University Press, 2009.

Teller, A. and Levin, Z.: Factorial method as a tool for estimating the relative contribution to precipitation of cloud microphysical processes and environmental conditions: Method and application, J. Geophys. Res.-Atmos., 113(13), D02202, doi:10.1029/2007JD008960, 2008.

Topping, D. O., McFiggans, G. B., and Coe, H.: A curved multicomponent aerosol hygroscopicity model framework: Part 1 - Inorganic compounds, Atmos. Chem. Phys., 5, 1205-1222, doi:10.5194/acp-5-1205-2005, 2005.

Twomey, S.: The influence of pollution on shortwave albedo of clouds, J. Atmos. Sci., 34, 1149-1152, 1977.

Twomey, S. A.: The Nuclei of Natural Cloud Formation. Part II: The Supersaturation in Natural Clouds and the Variation of Cloud Droplet Concentrations, Geofis. Pure Appl., 43, 227-242, 1959.

Tzivion, S., Feingold, G., and Levin, Z.: An efficient numericalsolution to the stochastic collection equation, J. Atmos. Sci., 44, 3139-3149, 1987.

van Zanten, M. C., Stevens, B. B., Nuijens, L., Siebesma, A. P., Ackerman, A., Burnet, F., Cheng, A., Couvreux, F., Jiang, H., Khairoutdinov, M., Kogan, Y., Lewellen, D. C., Mechem, D., Nakamura, K., Noda, A., Shipway, B. J., Slawinska, J., Wang, S., and Wyszogrodzki, A.: Controls on precipitation and cloudiness in simulations of trade-wind cumulus as observed during RICO, J. Adv. Model. Earth Syst., in press, 2011.

Wang, H. L. and McFarquhar, G. M.: Modeling aerosol effects on shallow cumulus convection under various meteorological conditions observed over the Indian Ocean and implications for development of mass-flux parameterizations for climate models, J. Geophys. Res.-Atmos., 113(20), D20201, doi:10.1029/2008JD009914, 2008. 